\title{
THE IMPACT OF HIGH-RESOLUTION SALLJEX DATA ON GLOBAL NCEP ANALYSES
}

\author{
Dirceu L. Herdies \\ Center for Weather Forecast and Climate Studies (CPTEC) \\ National Institute for Space Research (INPE) \\ Cachoeira Paulista, SP, Brazil
}

\author{
Vernon E. Kousky and Wesley Ebisuzaki \\ National Centers for Environmental Prediction (NCEP) \\ Climate Prediction Center (CPC) \\ Camp Springs, MD, USA
}

Submitted to J. Climate

February 2006

Corresponding Author: Dirceu L. Herdies

CPTEC/INPE

Rodovia Presidente Dutra km 40

12630 Cachoeira Paulista, SP Brazil

E-mail: dirceu@cptec.inpe.br 


\begin{abstract}
A data assimilation study was performed to assess the impact of observations from the South American Low-Level Jet Experiment (SALLJEX) on analyses in the region east of the Andes Mountains from western Brazil to central Argentina. The data assimilation systems, CDAS-1, CDAS-2 and GDAS, were run with and without the additional SALLJEX rawinsondes and pilot balloon observations. The experiments for each data assimilation system revealed similar features, with a stronger low-level flow east of the Andes when SALLJEX data were included. GDAS had the strongest LLJ when compared with observations. In the experiments which used additional rawinsonde and pilot balloons data, the LLJ was displaced westward in comparison to the analyses run without the SALLJEX data. The vertical structure of the meridional wind in the analyses was much closer to observed rawinsonde profiles in the experiments which included SALLJEX data than in the control experiments and the results show that, although there are more pilot balloon observations than rawinsonde observations in the SALLJEX dataset, most of the improvements in the analyses can be obtained by only including rawinsonde observations. This was especially true for GDAS. The results of this study can serve as a benchmark for similar data impact studies using higher resolution data assimilation systems.
\end{abstract}




\section{Introduction}

In recent years several studies demonstrated the important role that the South American Low-Level Jet (SALLJ) plays in transporting moisture from the Amazon Basin to higher latitudes over the continent. Many of these studies have utilized the National Centers for Environmental Prediction (NCEP) reanalysis data (e.g., Nogues-Paegle and Mo 1997; Berbery and Collini 2000; Marengo et al. 2004) and the European Centre for Medium-Range Weather Forecasts (ECMWF) reanalysis data (Salio et al. 2002; Wang and Fu 2004), as the basis for studying climate and climate variability. For data rich areas, the Climate Data Assimilation System (CDAS-1, Kalnay et al. 1996 and CDAS-2, Kanamitsu et al. 2002) provides a fairly homogeneous set of analyses spanning more than 50 years, which are ideal for climate studies. However, for data sparse regions, including many areas in the Southern Hemisphere, uncertainty exists concerning the validity of those analyses. The characteristics (parameterization, resolution, topography, etc) of the general circulation model (GCM), which serves as a nucleus of the data assimilation system, become increasingly important in determining circulation features as the spatial and temporal resolution of the observations decreases. Anderson and Arritt (2001), using the NCEP-NCAR reanalysis data to investigate the low-level jet (LLJ) in the Great Plains, pointed 
out the risk of using data analyzed at times when the analyses are heavily influenced by the GCM (times when observations are relatively sparse).

The South American Low-level Jet Experiment (SALLJEX) field campaign was carried out in western-central South America during the period 15 November 2002 -14 February 2003 (Vera et al. 2006). The SALLJ program, a component of CLIVAR/VAMOS, is an internationally coordinated effort to contribute to a better understanding of the role of the SALLJ in the moisture and energy exchanges between the tropics and extratropics, and to related aspects of the regional hydrology, climate and climate variability for the region of the South American Monsoon.

During SALLJEX a dense observation network was deployed with sixteen new pilot balloon stations and six new rawinsonde stations in Bolivia, Paraguay, central and northern Argentina, western Brazil and Peru (Fig. 1). Most rawinsonde sites operated twice daily (at 06 UTC and 18 UTC, and for Brazilian sites at 00 UTC and 12 UTC), except during the Intensive Observing Period (IOP) when some sites operated four times daily. These datasets were not available on the Global Telecommunication System (GTS) and, therefore, they can be used as an independent verification of the sensitivity of assimilation systems (NCEP, ECMWF and DAO/NASA).

The emphasis of this paper is on the impacts of high-resolution fieldexperiment data on the strength, position and structure of the low-level Jet east of the Andes, using the NCEP operational data assimilation systems. 
Specifically, comparisons are made between analyses produced with and without the SALLJEX data using the Climate Data Assimilation System (CDAS-1), that was used in the NCEP/NCAR Reanalysis Project (Kalnay et al. 1996), CDAS-2 that was used in the Reanalysis-2 Project (Kanamitsu et al. 2002) and a reduced resolution version of the operational NCEP Global Data Assimilation System (GDAS). The present results will serve as a benchmark for similar data impact studies using higher resolution regional data assimilation systems. The data sources and methodology, used to assimilate the data, and a brief description of some aspects of the assimilation systems used are described in section 2 . Section 3 describes the impact of SALLJEX data on the analyses derived from the global data assimilation systems. The results are described in section 4, and discussion and conclusions are presented in section 5 .

\section{Data Sets and Methods}

\section{a) SALLJEX Observations}

The SALLJEX field campaign took place during 15 November 2002-14 February 2003 over west-central South America east of the Andes Mountains. Enhanced (temporal and spatial) atmospheric soundings were made over Argentina, Bolivia, Brazil, Paraguay and Peru. These included twenty-two new upper air observation stations, with sixteen pilot balloon (PIBAL) and six rawinsonde (RAOB) stations (Fig. 1). Most RAOB stations operated twice daily 
(06 UTC and 18 UTC) while PIBAL stations operated four times daily during the Special Observation Period (SOP) 6 January-14 February 2003. During the Intensive Observation Period (IOP) most RAOB sites operated 3-4 times daily and up to 8 PIBAL ascents per day were made at selected sites. These observations were not available on the Global Telecommunications System (GTS) and were not assimilated into any operational analysis systems in real time. They are used here as an independent verification of the NCEP assimilation systems (CDAS and GDAS). Table 1 shows the soundings that were used by CDAS and GDAS during the period 15 December 2002-14 February 2003.

\section{b) Global Data Assimilation Systems}

The basic idea of reanalysis is to use a frozen state-of-the-art analysis/forecast system to perform data assimilation using past data. In this study we compare the analyses, derived from three different data assimilation systems (CDAS1, CDAS2 and GDAS), for the period 15 December 2002-14 February 2003.

CDAS1 is the frozen analysis/forecast system that was used to perform the NCEP/NCAR reanalysis (R-1, Kalnay et al. 1996) for the period 1948 to present. CDAS2 is an updated NCEP/NCAR reanalysis (R-2, Kanamitsu et al. 2002), covering 1979 to present, with an improved forecast model and data 
assimilation system. GDAS is a reduced resolution version of the operational NCEP global model data assimilation system (version 2005).

The resolutions of the systems are T62L28 for CDAS, approximately 250 $\mathrm{km}$ horizontal resolution with 28 levels in the vertical, and T170L42 for GDAS, approximately $100 \mathrm{~km}$ horizontal resolution with 42 levels in the vertical.

\section{c) Experiments}

In order to assess the impact that the introduction of the SALLJEX dataset has on the analyses, the following experiments were performed, using CDAS1, CDAS2 and GDAS:

1) control runs without the SALLJEX data;

2) runs only including RAOB data (CDAS1r, CDAS2r and GDASr);

3) runs including all SALLJEX upper-air data, RAOB and PIBAL (CDAS1rp, CDAS2rp and GDASrp);

4) runs only including PIBAL in GDAS (GDASp).

All the variables from the SALLJEX RAOB (meridional and zonal wind, specific humidity and temperature) and PIBAL (meridional and zonal wind) have been incorporated in the data assimilation systems.

\section{Regional Impact of SALLJEX}


The use of global reanalysis, which combines general circulation model (GCM) predictions with observations, is a powerful tool for understanding many climate and weather questions that would otherwise remain elusive because of the limited availability of the data over some regions. However, due to differences in data assimilation systems (models and assimilation techniques) there is a degree of uncertainty in the reanalyzed fields. An example of this uncertainty is pointed out in Fig. 2, which shows the low-level (850-hPa) vector wind over South America during the period 15 January-14 February 2003. The strength of the low-level flow east of the Andes mountains varies by up to $40 \%$ in the analyses, with CDAS2 (Fig. 2b) having the strongest jet and GDAS, the operational data assimilation system, having the weakest jet Fig. 2c). Figures $2 d, 2 e$ and $2 f$ show the impact of including SALLJEX data in CDAS1, CDAS2 and GDAS, respectively. The influence of SALLJEX data is concentrated over the region where the $\mathrm{RAOB}$ and PIBAL observations were made (Fig. 1) and the global influence is close to zero outside of the region (not shown). The strength and location of the core of the low-level jet analyzed in the three systems, CDAS1rp, CDAS2rp and GDASrp (Figs. 2d, 2e and 2f), are in better agreement than in the control runs, CDAS1,CDAS2 and GDAS (Figs. 2a, 2b and 2c).

The results in Figs. $2 d, 2 e$ and $2 f$ show that including the special RAOB and PIBAL observations does not appreciably affect the large-scale circulation pattern over the South American region. However, there is a discernable effect on the intensity of the northwesterly flow (LLJ) east of the Andes, with stronger winds in all cases where SALLJEX data have been included (right hand panels in 
Fig. 2). There are also notable differences in the cross-jet structure between the higher resolution GDAS analysis and the lower resolution CDAS analyses. GDASrp (Fig. 2f) shows a narrower jet, with wind speeds greater than $8 \mathrm{~m} \mathrm{~s}^{-1}$, concentrated near the Andes close to Santa Cruz, Bolivia. CDAS1rp and CDAS2rp (Figs. 2d and 2e, respectively) also show a stronger jet but farther away from the Andes. These differences in LLJ location are probably related to differences in resolution between CDAS and GDAS and how the Andes mountains are depicted in the model.

An examination of the vertical structure of the mean meridional wind at $18^{\circ} \mathrm{S}, 62^{\circ} \mathrm{W}$ (near Santa Cruz) reveals that the maximum impact of including SALLJEX data occurs at low levels at 06 UTC in GDAS (Fig. 3b). The added effect of including PIBAL with RAOB data has little impact when compared with RAOB alone, except at 18 UTC in GDAS (Fig. 3d). Including SALLJEX data noticeably increases the amplitude of the diurnal cycle in the strength of the LLJ, with a maximum strength near $900 \mathrm{hPa}$ between 06 UTC and 12 UTC in GDAS and at $850 \mathrm{hPa}$ near 06 UTC in CDAS1 and CDAS2. The mean altitude of the maximum low-level wind increases from 06 UTC to 18 UTC in GDAS, a feature not evident in CDAS1 and CDAS2. The effects of including SALLJEX data are least at 00 UTC in GDAS and CDAS2 and at 12 UTC in CDAS1. This is probably related to the lack of $\mathrm{RAOB}$ observations at these times (Table 1), which contributes to increased uncertainty in the analyses.

Figure 4 shows the diurnal cycle of the mean meridional wind at $900 \mathrm{hPa}$ for GDAS and at $850 \mathrm{hPa}$ for CDAS1 and CDAS2 averaged for the period 15 
January - 14 February 2003. The effect of including SALLJEX RAOB data in GDAS increases the strength of the jet, especially at 06 UTC (blue line in Fig. 4a). Only slight differences in the strength of the low-level meridional wind result when the PIBAL data are included together with RAOB data (compare the blue and green lines in Fig. 4a).

Similar results are found for a point near Mariscal, Paraguay at $22^{\circ} \mathrm{S}$, 60ํㅡ (Fig. 5). The greatest effect of including SALLJEX data can be observed at 06 UTC in all assimilation systems, with the maximum jet intensity occurring between 06 UTC and 12 UTC. There is little difference in the wind speeds between the control runs and the runs including SALLJEX data at 00 UTC and 12 UTC due to a lack of SALLJEX observations at those times (Table 1).

\section{a) Case study: Mesoscale Convective Complex on 22 January 2003}

To further illustrate some characteristics of the difference between the analysis and control experiments, we consider the case of an intense Mesoscale Convective Complex (MCC) that developed on 22 January 2003 over northeast Argentina, which produced heavy rainfall amounts as it propagated eastward across Paraguay and southwest Brazil during the nighttime hours (Zipser et al. 2004).

Figure 6 compares the vertical structure of the observed meridional wind (blue dots) at Mariscal (approximately at $22^{\circ} \mathrm{S}, 60 \mathrm{w}$ ) with GDAS (black - long dash), GDASrp (green), CDAS2 (red - long dash) and CDAS2rp (dark yellow) for 
the period of 18 UTC (22 January), 00 UTC (23 January) and 06 UTC (23 January). It is important to note that Mariscal operated as a rawinsonde station at 06 UTC and 18 UTC. The GDASrp analyses show stronger low-level flow near $900 \mathrm{hPa}$ in agreement with the observations and a well defined LLJ at 06 UTC. The strength of the low-level flow is much weaker in GDAS, CDAS2 and CDAS2rp. The state-of-the-art GDAS seems to be better at assimilating the SALLJEX data, thereby improving the representation of the LLJ in GDASrp. The low-resolution CDAS is not able to take advantage of the additional sounding data to improve the low-level circulation features. Furthermore, the low-resolution CDAS is not able to adequately resolve the topography (Andes Mountains), which also can affect the intensity and position of the LLJ (Anderson et al. 2001).

The moisture fluxes in GDASrp are noticeably stronger (on the order of 30 $\mathrm{gm} \mathrm{kg}^{-1} \mathrm{~m} \mathrm{~s}^{-1}$ ) than those in the control run (GDAS) at all three times (Fig 7). There is also a slight westward shift in the maximum flux in the GDASrp analyses. This shift is accompanied by stronger upward motion in GDASrp (Fig . 8, compare left and middle panes), which corresponds well with the pattern of precipitation (Fig. 8, right panel) taken from the CMORPH analyses (Joyce et al. 2004). The CDAS analyses (with and without SALLJEX data) were not able to capture the circulation features (moisture flux and vertical motion) associated with the intense MCC (figure not shown).

\section{Comparison with Observations}


A comparison between the observed $850-\mathrm{hPa}$ specific humidity at Santa Cruz (see Fig. 1 for station location) with the analyses from GDAS, CDAS1, and CDAS2, shows that GDASrp fits well with the RAOB data (compare blue triangles with red curve in Fig. 9a), even better than the operational GDAS (green curve in Fig. 9a). Both the operational GDAS and GDASrp capture well the features associated with a strong southerly jet, which occurred during the dry period 23-24 January. In general the differences between GDAS and GDASrp are less than $2 \mathrm{~g} \mathrm{~kg}^{-1}$.

The biggest differences between the observations and the analyses occur in CDAS1 and CDAS2 (Figs. 9b, 9c). CDAS1 shows a much stronger diurnal cycle than that shown in the observations. There is also a positive bias in the specific humidity with values greater than $20 \mathrm{~g} \mathrm{~kg}^{-1}$, as compared to $15 \mathrm{~g} \mathrm{~kg}^{-1}$ in the observations (Fig. 9b). There is no significant impact on the CDAS1 analyses when the SALLJEX dataset are included. Similar results are observed with CDAS2, but the diurnal cycle is not as strong as in CDAS1 and CDAS1rp.

Kalnay et al. (1996) classified the gridded fields into four classes, in accordance with the relative influence of the observational data and the model on the gridded variable. Specific humidity is considered a class "B" variable, as the model has a very strong influence on its analysis value. Thus, one would expect that the more advanced GDAS, with improved physics, higher resolution and improved data assimilation procedures, would better capture specific humidity variations. 
Figure 10 shows the $850-\mathrm{hPa}$ meridional wind component for GDAS, GDASrp, CDAS1, CDAS1rp, CDAS2, CDAS2rp and the observations. The largest differences occur after the middle of January and extend until the end of the month (Fig. 10a), which is the period having the highest number of RAOB observations (Table 1). GDASrp agrees very well with the RAOB data and captures the maximum and minimum (Fig. 10a) associated with the southerly and northerly low-level jet, respectively. In general the control run, GDAS, underestimates the magnitude of the meridional wind.

Both CDAS1 and CDAS2 (Figs. 10b and 10c) are unable to capture the extreme values (maximum and minimum) of the $850-\mathrm{hPa}$ meridional wind at the grid point nearest to Santa Cruz. For the CDAS1rp and CDAS2rp the differences are small and the meridional winds are generally underestimated. The worst case is associated with the strong, southerly low-level flow during 23-24 January. The observed values are close to $20 \mathrm{~m} \mathrm{~s}^{-1}$, and for CDAS1 and CDAS2 the maximum values are $5 \mathrm{~m} \mathrm{~s}^{-1}$ and $3 \mathrm{~m} \mathrm{~s}^{-1}$, respectively. For CDAS1rp and CDAS2rp the values are a little closer to the observed values, $9 \mathrm{~m} \mathrm{~s}^{-1}$ and $10 \mathrm{~m} \mathrm{~s}^{-1}$, respectively.

The specific humidity results for Mariscal in northern Paraguay (Fig. 11) are better than for Santa Cruz (Fig. 9) in all assimilation systems (GDAS, CDAS1 and CDAS2) (green lines in Figs. 11a, 11b and 11c, respectively). The results are much better when the SALLJEX data are included and are close to the observed values (red lines in Figs. 11a, 11b and 11c). The better results from CDAS over Mariscal (see Fig. 1 for station location) is probably due to this station 
being located farther away from the Andes, which reduces the effects of model topography on the low-level flow.

The largest differences in specific humidity between CDAS1 and CDAS1rp, values close to $5 \mathrm{~g} \mathrm{~kg}^{-1}$, occurred during the last week of January when the SACZ was well defined over Southeast Brazil and southerly winds and low specific humidity prevailed over Mariscal and Santa Cruz. This relationship between specific humidity and low-level wind are consistent with previous results (Nogués-Paegle and Mo 1997; Herdies et al. 2002).

The meridional wind results for Mariscal (Fig. 12) are similar to those for Santa Cruz (Fig. 10). Again CDAS1 and CDAS2 underestimate the extreme maximum and minimum $850-\mathrm{hPa}$ wind speeds, but they capture well the day-today variations. The GDAS results are better and do not show a lot of changes when the SALLJEX data are included (Fig. 12). CDAS1rp and CDAS2rp also are in good agreement with the observations (Figs. 12a and 12b, respectively).

With the additional soundings the improvements in the LLJ region are significant and the largest impacts are on the Santa Cruz region (Table 2), where the CDAS and GDAS have the largest uncertainties (RMSE). All the simulations show a negative bias (simulation - observation; Table 2) for the zonal wind component but the biases are significantly reduced with the inclusion of the SALLJEX sounding data. The largest RMSE for the zonal wind is found for CDAS2 (7.9) follow by GDAS (7.0) that are reduced to less than $60 \%(4.9)$ in CDAS2r and to less than $40 \%$ in GDASr (2.9). 
For the meridional wind component, all the simulations show a positive bias (underestimate of the LLJ) for the Santa Cruz region. It is apparent that all the simulations have similar RMSE (near 5.5), but with the additional SALLJEX sounding data improvements in GDASr and GDASrp are more substantial (1.9 and 2.3, respectively), indicating that GDAS is more capable of including the information from the soundings. With the inclusion of PIBAL additional improvements are minor for the $u$ and $v$ wind components.

At Mariscal the differences are smaller than those of Santa Cruz and for all simulations the biases are positive, showing a similar pattern for the meridional wind component as at Santa Cruz. The RMSE is similar for both wind components after the inclusion of SALLJEX sounding data, indicating that all the assimilation systems are able to incorporate information from the special soundings.

Figure 13 compares the observed and SALLJEX assimilated analyses of 850-hPa meridional moisture flux over Santa Cruz and Mariscal. For Mariscal the moisture flux for all assimilation systems is close to the observations (Fig. 13a), with CDAS1 generally overestimating the moisture flux, but doing much better when the additional sounding data are included (Fig. 13b), with extremes from $150\left(\mathrm{~g} \mathrm{~kg}^{-1} \mathrm{~m} \mathrm{~s}^{-1}\right)$ from the south to $120\left(\mathrm{~g} \mathrm{~kg}^{-1} \mathrm{~m} \mathrm{~s}^{-1}\right)$ from the north. Santa Cruz shows a stronger transport from the north when compared with values at Mariscal (Figs. 13c and 13d). The strongest transport occurs during the period 20-22 January (Fig. 13d), which resulted in the formation of strong mesoscale convective systems over northern Argentina and Paraguay during 20-22 January 
(Zipser et al. 2004). I is clear that none of the analysis systems were able to capture the strongest transport values without including SALLJEX data (Fig. 13c). During the period of study there is some evidence that the transport over Santa Cruz is more intense than over Mariscal, where GDASrp is in good agreement with the observations (Fig. 13d) and moisture flux is underestimated by CDAS1rp and CDAS2rp.

\section{a) The Influence from Rawinsonde and Pilot Balloon}

Two experiments were done to investigate the impact of including SALLJEX rawinsonde and pilot balloon observations separately. GDAS was chosen for these experiments, since the greatest effects of including SALLJEX data are evident for that assimilation system (refer to Fig. 3).

Figure 14 shows the difference between the control analysis (GDAS) and the analysis that assimilated only RAOB (GDASr) for the synoptic times $(00,06$, 12 and 18 UTC) averaged over 15 January to 14 February 2003. The influence from RAOB is clearly seen in the region east of the Andes, which includes the stations of Santa Cruz and Mariscal (for station locations, see Fig. 1). There is little impact of including the RAOB data over northern South America, eastern Brazil or oceanic areas. The most significant effects are at 06 UTC (Fig. 14c and 14d) near $850 \mathrm{hPa}$, as show in the vertical cross sections displayed in the righthand panels of Fig. 14. The mean sensitivity locally exceeds $3 \mathrm{~m} \mathrm{~s}^{-1}$, and the 
strongest influence is at 06 UTC and 18 UTC (Figs. 14d and 14h), apparently due to the availability of rawinsonde data at Santa Cruz at those times (Table 1).

Figure 15 displays the results of the assimilation of SALLJEX pilot balloon observations. The strongest effects are again observed around 06 UTC and 18 UTC, but they are somewhat weaker than those related to the rawinsonde observations (Fig. 14).

These results show that, although there are more pilot balloon observations than rawinsonde observations in the SALLJEX dataset, most of the improvements in the analyses can be obtained by only including rawinsonde observations. It is possible that the pilot balloon observations were not as heavily weighted as the rawinsondes by the assimilation systems. The former observations are not easily available at night or above clouds and provide neither thermal nor moisture data that can be crucial to define the humidity transport from the tropics to extratropics.

\section{Conclusion}

A data assimilation study was performed to assess the impact of observations from the South American Low-Level Jet Experiment (SALLJEX) on analyses in the region east of the Andes Mountains from western Brazil to central Argentina. The data assimilation systems, CDAS1, CDAS2 and GDAS, were run with and without the additional SALLJEX rawinsondes and pilot balloon observations (Fig. 1). This evaluation is crucially important to examine the impact 
of high-resolution field experiment data on the NCEP global analysis and the ability of state-of-the-art data assimilation systems to correctly analyze important climatic features of a major monsoon system.

Most of the effects on the reanalysis that include additional SALLJEX data are regional and concentrated over the SALLJ region, with the largest differences at low levels. All assimilation systems showed improvements in the SALLJ when SALLJEX data were included. The differences between CDAS1rp and CDAS2rp are small when compared with the respective control runs. The largest effects for all assimilation systems appear where the uncertainties are large, which usually occurs when there is a lack of routine upper-air observations.

The coarse resolutions of CDAS1 and CDAS2 (T62 $250 \mathrm{~km})$ do not adequately resolve the Andes Mountains, and, as a result, CDAS systems were unable to exploit the additional sounding data from Santa Cruz to improve the characteristics of the low-level jet and associated moisture transport. CDAS systems displayed only minor analysis improvements when the enhanced SALLJEX sounding data were included, with CDAS2 showing a little improvement over CDAS1. Also, CDAS systems clearly overestimate the specific humidity in control runs, which was not corrected when SALLJEX data were included.

For all three assimilation systems the inclusion of pilot balloon data does not significantly improve analyses over those produced using only rawinsonde data. In part this may be due to the fact that the pilot balloon ascents use the first guess from the models to locate the correct pressure levels, using the height 
information provided from pilot balloon. This process can include some error and it is possible that in some cases the pilot balloon data were not assimilated because of data rejection criteria.

Some fields, such as winds, temperature and geopotential height, are generally well defined by observations and, given the statistical interpolation of the observations and first guess, the reanalyzed fields are the best estimate of the evolving state of the atmosphere, which is even better than would be obtained using only observations. For others, such as moisture variables, the model characteristics, which influence the model climatology, become more important (Kalnay et al. 1996).

For the global analyses, the GDAS provides the best results because of its higher resolution and state-of-the-art data assimilation system, which is more effective in assimilating satellite data, such as radiances. GDASrp shows a narrow jet concentrated near the Andes with the maximum speed close to Santa Cruz. Silva Dias et al. (2001) found similar results indicating that the higherresolution model confines the low-level jet to a narrower strip along the Andes. The diurnal cycle in the strength of the LLJ is more evident, with the maximum strength at 0600 UTC near $900 \mathrm{hPa}$ in GDAS and $850 \mathrm{hPa}$ in CDAS.

The data impact results for Mariscal in northern Paraguay show considerable improvement in the wind and humidity analyses, especially for CDAS. The better results for CDAS1 and CDAS2 at Mariscal are probably due to the greater distance of that site from the Andes, which minimizes the effects of the model topography. The significant reduction of RMS errors at Santa Cruz 
and Mariscal show the ability of the GDAS to assimilate additional sounding data into the analysis.

The results show that, although there are more pilot balloon observations than rawinsonde observations in the SALLJEX dataset, most of the improvements in the analyses can be obtained by only including rawinsonde observations.

The reanalysis dataset produced in this study using the information from SALLJEX has the potential to provide the best possible information to be used for future studies at SALLJ region and can be used for the design of the observing systems in the region. This paper points out the importance of regular observations from the region of Santa Cruz to properly depict the position and intensity of the SALLJ.

All of the datasets used in this study are available at JOSS/UCAR for distribution and use in additional validation/evaluation studies in the future.

Acknowledgments. The authors wish to acknowledge Dennis Keyser for his excellent support in incorporating the SALLJEX data into the assimilation systems and the efforts of the anonymous reviewers and the associate editor who greatly helped improve the manuscript. The first author wishes to acknowledge the support of the Earth System Science Interdisciplinary Center (ESSIC) and NCEP for providing the necessary conditions to develop this study and to funding agencies from Brazil (CNPq Grant 481400/2004-04 and CAPES Grant 3219-04-6). SALLJEX was funded by NOAA/OGP, NSF (ATM0106776), 
and funding agencies from Brazil (FAPESP Grant 01/13816-1) and Argentina (ANPCYT 07-06671, UBA 055). This work was partially supported by the NOAA Office of Global Programs Pan American Climate Studies (PACS) under Cooperative Agreement NA17EC1483 with the University of Maryland Cooperative Institute for Climate Science (CICS). 


\section{References}

Anderson, C. J., and R. Arrit, 2001: Representation of summertime low-level jets in the central United States by NCEP-NCAR reanalysis. J. Climate, 14, 234247.

Berbery, E. H., and E. A. Collini, 2000: Springtime precipitation and water vapor flux over southeastern South America. Mon. Wea. Rev., 128, 1328-1346.

Bonner, W. D., 1968: Climatology of the low level jet. Mon. Wea. Rev., 96, 833850.

Herdies, D. L., A. da Silva, M. A. F. Silva Dias, and R. Nietto Ferreira, 2002: Moisture budget of the bimodal pattern of the summer circulation over South America. J. Geophys. Res., 107, 8075, doi: 10.1029/2001JD000997.

Joyce, R. J., J. E. Janowiak, P. A. Arkin, and P. Xie, 2004: CMORPH: A method that produces global precipitation estimates from passive microwave and infrared data at high spatial and temporal resolution. J. Hydromet., 5, 487503.

Kalnay, E., and Coauthors, 1996: The NCEP/NCAR 40-Year Reanalysis Project. Bull. Amer. Meteor. Soc., 77, 437-471.

Kanamitsu, M., W. Ebisuzaki, J. Woollen, S. K. Yang, J. J. Hnilo, M. Fiorino, and G. L. Potter, 2002: NCEP-DOE AMIP-II reanalysis (R-2). Bull. Amer. Meteor. Soc., 83, $1631-1643$. 
Marengo, J. A., W. R. Soares, C. Saulo, and M. Nicolini, 2004: Climatology of the low-level jet east of the Andes as derived from NCEP-NCAR reanalysis: Characteristics and temporal variability. J. Climate, 17, 2261-2280.

Nogués-Paegle, J., and K. C. Mo, 1997: Alternating wet and dry conditions over South America during summer. Mon. Wea. Rev., 125, 279-291.

Salio, P., M. Nicolini, and C. Saulo, 2002: Chaco low-level jet events characterization during the austral summer season. J. Geophys. Res., 107, 4816, doi: $10.1029 / 2001 J D 001315$.

Silva Dias, P. L., D. Moreira, and M. A. F. Silva Dias, 2001: Downscaling resolution and the moisture budget of the Plata basin. IX Congreso Latinoamericano e Iberico de Meteorologia y Congreso Argentino de Meteorologia. La Meteorologia y el Medio Ambiente en el Siglo XXI, Buenos Aires, Argentina, Centro Argentino de Meteorológos, CD-ROM, 8.C.27-341.

Vera, C., and Coauthors, 2006: The South American low-level jet experiment. Bull. Amer. Meteor. Soc., 87, 63-77

Zipser, E., P. Salio, and M. Nicolini, 2004: Mesoscale convective systems activity during SALLJEX and the relationship with SALLJEX events. CLIVAR Exchanges, Vol. 9, No. 1, International CLIVAR Project Office, 14-18.

Wang, H., and R. Fu, 2004: Influence of cross-Andes flow on the South American low-level jet. J. Climate, 17, 1247-1262. 
Table 1. SALLJEX soundings those were included in the assimilation system.

\begin{tabular}{|c|c|c|c|c|c|c|c|c|c|c|c|c|c|c|c|c|c|c|c|c|c|c|c|c|}
\hline \multirow{2}{*}{$\begin{array}{l}\text { Stations } \\
\text { Day }\end{array}$} & \multicolumn{4}{|c|}{$\begin{array}{c}\text { Mariscal } \\
\text { UTC }\end{array}$} & \multicolumn{4}{|c|}{$\begin{array}{c}\text { Santa Cruz } \\
\text { UTC }\end{array}$} & \multicolumn{4}{|c|}{$\begin{array}{c}\text { Dourados } \\
\text { UTC }\end{array}$} & \multicolumn{4}{|c|}{$\begin{array}{c}\text { Rio Branco } \\
\text { UTC }\end{array}$} & & $\begin{array}{r}\text { Sant } \\
\text { UT }\end{array}$ & íago & & & U & $\begin{array}{l}\text { tenc } \\
\text { TC }\end{array}$ & \\
\hline & $00 \quad 0$ & 061 & 121 & 18 & 00 & 06 & 12 & 18 & 0 & 06 & 12 & 18 & 0 & $0 \quad 06$ & & 18 & 00 & 06 & 12 & 18 & $0 C$ & 06 & 12 & 18 \\
\hline Dec 15, 2002 & & & & & & & & & & & & & & & & & & $\mathrm{x}$ & & & & $\mathrm{X}$ & & \\
\hline Dec 16, 2002 & & & & & & & & & & & & & & & & & & $x$ & & & & $\mathrm{X}$ & & \\
\hline Dec 17, 2002 & & $\bar{x}$ & & & & & & & & & & & & & & & & $\mathrm{x}$ & & & & $\mathrm{X}$ & & \\
\hline Dec 18, 2002 & & $x$ & & $x$ & & & $\mathrm{x}$ & & & & & & & & & & & $\mathrm{x}$ & & & & $\mathrm{X}$ & & \\
\hline $\operatorname{Dec} 19,2002$ & & $x$ & & $x$ & & & $\mathrm{x}$ & & & & & & & & & & & $\mathrm{x}$ & & & & $\mathrm{X}$ & & \\
\hline Dec 20, 2002 & & $x$ & & & & & & & & & & & & & & & & $\mathrm{x}$ & & & & $\mathrm{X}$ & & \\
\hline Dec 21, 2002 & & $\mathrm{x}$ & & & & & $\mathrm{x}$ & & & & & & & & & & & $\mathrm{x}$ & & & & $\mathrm{X}$ & & \\
\hline Dec 22, 2002 & & $x$ & & & & & $\mathrm{x}$ & & & & & & & & & & & $\mathrm{x}$ & & & & . & & \\
\hline Dec 23, 2002 & & $\bar{x}$ & & & & & & & & & & & & & & & & $\mathrm{x}$ & & & & & & \\
\hline Dec 24, 2002 & & $\bar{x}$ & & & & $\mathrm{x}$ & & & & & & & & & & & & $\mathrm{x}$ & & & & & & \\
\hline Dec 25, 2002 & & $\bar{x}$ & & & & & & & & & & & & & & & & $\mathrm{x}$ & & & & $\mathrm{X}$ & & \\
\hline Dec 26, 2002 & & $\mathrm{x}$ & & & & $\mathrm{x}$ & & & & & & & & & & & & $x$ & & & & $X$ & & \\
\hline Dec 27, 2002 & & $x$ & & & & $\mathrm{x}$ & & & & & & & & & & & & $\mathrm{x}$ & & & & $\mathrm{X}$ & & \\
\hline Dec 28, 2002 & & $\bar{x}$ & & & & $\mathrm{x}$ & & & & & & & & & & & & $\mathrm{x}$ & & & & $\mathrm{X}$ & & \\
\hline Dec 29, 2002 & & $\bar{x}$ & & & & $\mathrm{x}$ & & & & & & & & & & & & & & & & $\mathrm{X}$ & & \\
\hline Dec 30, 2002 & & $\bar{x}$ & & & & $\mathrm{X}$ & & & & & & & & & & & & $\mathrm{x}$ & & & & $\mathrm{X}$ & & \\
\hline Dec 31, 2002 & & $x$ & & & & & & & & & & & & & & & & $\mathrm{x}$ & & & & $\mathrm{X}$ & & \\
\hline $\operatorname{Jan} 01,2003$ & & $x$ & & & & & & & & & & & & & & & & $\mathrm{x}$ & & & & $\mathrm{X}$ & & \\
\hline Jan 02,2003 & & $\bar{x}$ & & & & & & & & & & & & & & & & $\mathrm{x}$ & & & & $\mathrm{X}$ & & \\
\hline $\operatorname{Jan} 03,2003$ & & $\mathrm{x}$ & & & & & & & & & & & & & & & & $\mathrm{x}$ & & & & $x$ & & \\
\hline Jan 04, 2003 & & $x$ & & & & & & & & & & & & & & & & $\mathrm{x}$ & & & & $\mathrm{X}$ & & \\
\hline Jan 05, 2003 & & $\mathrm{x}$ & & & & & & & & & & & & & & & & $\mathrm{x}$ & & & & $\mathrm{X}$ & & \\
\hline Jan 06, 2003 & & $x$ & & $x$ & & & & & & & & & & & & & & $\mathrm{x}$ & & & & $\mathrm{X}$ & & \\
\hline Jan 07, 2003 & & $x$ & & $x$ & & & & & $\mathrm{x}$ & & & & $x$ & & & & $\mathrm{x}$ & $\mathrm{x}$ & & & & $\mathrm{X}$ & & \\
\hline $\operatorname{Jan} 08,2003$ & & & & $\mathrm{x}$ & & & & & $x$ & & & & $x$ & & & & & $\mathrm{x}$ & & $x$ & & $\mathrm{X}$ & & \\
\hline Jan 09, 2003 & & & & $\mathrm{X}$ & & & & & $\mathrm{x}$ & & & & $x$ & & & & & $\mathrm{X}$ & & $\mathrm{X}$ & & $\mathrm{X}$ & & \\
\hline $\operatorname{Jan} 10,2003$ & & $\mathrm{x}$ & & $x$ & & & & & $\mathrm{x}$ & & & & $x$ & & & & & $\mathrm{x}$ & & $x$ & & $\mathrm{X}$ & & $x$ \\
\hline $\operatorname{Jan} 11,2003$ & & $x$ & & $x$ & & & & & $\mathrm{x}$ & & & & $\mathrm{x}$ & & & & & $\mathrm{x}$ & & $x$ & & $x$ & & $x$ \\
\hline $\operatorname{Jan} 12,2003$ & & $\bar{x}$ & & $\mathrm{x}$ & & & & & $\mathrm{x}$ & & & $x$ & $\mathrm{x}$ & & & $\mathrm{x}$ & & & & & & $\mathrm{x}$ & & $\mathrm{x}$ \\
\hline $\operatorname{Jan} 13,2003$ & & & & $\mathrm{x}$ & & & & & $\mathrm{x}$ & & & & $\mathrm{x}$ & & & & & $\mathrm{x}$ & & $\mathrm{x}$ & & $\mathrm{x}$ & & $\bar{x}$ \\
\hline $\operatorname{Jan} 14,2003$ & & & & $x$ & & & & & & & & & $x$ & & & & & $\mathrm{x}$ & & $x$ & & $x$ & & $\bar{x}$ \\
\hline Jan 15, 2003 & & $\mathrm{x}$ & & $\mathrm{x}$ & & $\mathrm{x}$ & & $x$ & $\mathrm{x}$ & & $\mathrm{x}$ & $x$ & $x$ & & $\mathrm{x}$ & $x$ & & $\mathrm{x}$ & & $x$ & & $\mathrm{x}$ & & $x$ \\
\hline Jan 16, 2003 & & $\mathrm{x}$ & & & & $\mathrm{x}$ & & $x$ & & $x$ & $x$ & & & $x$ & $\mathrm{x}$ & $\mathrm{x}$ & & $\mathrm{x}$ & & $\mathrm{x}$ & & $\mathrm{x}$ & & $\mathrm{x}$ \\
\hline Jan 17, 2003 & & $\bar{x}$ & & $\mathrm{X}$ & & $\mathrm{X}$ & & $x$ & & $\mathrm{X}$ & $\mathrm{X}$ & $x$ & & $x$ & $\mathrm{X}$ & $\mathrm{X}$ & & $\mathrm{X}$ & & $x$ & & $\mathrm{x}$ & & $x$ \\
\hline $\operatorname{Jan} 18,2003$ & & $\bar{x}$ & & $x$ & & $\mathrm{x}$ & & $x$ & & $x$ & $\mathrm{x}$ & & & $\bar{x}$ & & & & & & $x$ & & $\mathrm{x}$ & & $\bar{x}$ \\
\hline Jan 19, 2003 & & $\bar{x}$ & & $x$ & & $\mathrm{x}$ & & $x$ & $\mathrm{x}$ & & & & $x$ & & & & & $\mathrm{x}$ & & $x$ & & $\mathrm{x}$ & & $\bar{x}$ \\
\hline Jan 20, 2003 & & $\mathrm{x}$ & & $\mathrm{x}$ & & $\mathrm{x}$ & & $x$ & $\mathrm{x}$ & & & & $\mathrm{x}$ & & & & & $\mathrm{x}$ & & $x$ & & $\mathrm{x}$ & & \\
\hline Jan 21, 2003 & & & & $x$ & & $\mathrm{x}$ & & $x$ & $\mathrm{x}$ & & $x$ & $\bar{x}$ & $x$ & & $\mathrm{x}$ & $\bar{x}$ & & $\mathrm{x}$ & $\mathrm{x}$ & $\bar{x}$ & & $\mathrm{x}$ & & $\bar{x}$ \\
\hline Jan 22, 2003 & & $\bar{x}$ & & $\mathrm{X}$ & & & & $\mathrm{x}$ & & $\mathrm{X}$ & $\mathrm{X}$ & $x$ & & $\mathrm{x}$ & $\mathrm{X}$ & $\mathrm{x}$ & $x$ & $\mathrm{X}$ & $\mathrm{x}$ & $\mathrm{x}$ & $\mathrm{x}$ & $\mathrm{x}$ & $\mathrm{x}$ & \\
\hline Jan 23, 2003 & & $x$ & & $x$ & & & & $x$ & & $x$ & $x$ & $x$ & & $x$ & $\mathrm{x}$ & $\mathrm{x}$ & $x$ & $\mathrm{x}$ & $x$ & $x$ & & $\mathrm{x}$ & $\mathrm{x}$ & $\bar{x}$ \\
\hline Jan 24, 2003 & & $x$ & & & & & $x$ & $x$ & & $x$ & $x$ & $x$ & & $x$ & $\mathrm{x}$ & $\mathrm{x}$ & $x$ & $\mathrm{x}$ & $x$ & $\mathrm{x}$ & $x$ & $\mathrm{x}$ & $\mathrm{x}$ & $\mathrm{x}$ \\
\hline Jan 25, 2003 & & & & & & $\mathrm{x}$ & & $x$ & & $x$ & $\mathrm{x}$ & & & $x$ & $\mathrm{x}$ & & $x$ & $x$ & $x$ & $x$ & $\mathrm{x}$ & $x$ & & $\bar{x}$ \\
\hline Jan 26, 2003 & & & & $x$ & & & & & $\mathrm{x}$ & & & & $x$ & & & & & $\mathrm{x}$ & & $x$ & & $\mathrm{x}$ & & $x$ \\
\hline Jan 27, 2003 & & $\mathrm{x}$ & & $\mathrm{x}$ & & & & & $\mathrm{x}$ & & & & $x$ & & & & & $\mathrm{x}$ & & $\mathrm{x}$ & & $\mathrm{x}$ & & $\mathrm{x}$ \\
\hline Jan 28, 2003 & & $\bar{x}$ & & $\mathrm{x}$ & & $x$ & & $x$ & $x$ & & & & $\bar{x}$ & & & & & $x$ & & $x$ & & $\mathrm{x}$ & & $\bar{x}$ \\
\hline $\begin{array}{l}\text { Jan } 29,2003 \\
\text { Jan } 30,2003\end{array}$ & & $\begin{array}{l}x \\
x\end{array}$ & & & & $\begin{array}{l}\mathrm{x} \\
\mathrm{x}\end{array}$ & & $\begin{array}{l}\mathrm{x} \\
\mathrm{x}\end{array}$ & $\begin{array}{l}\mathrm{x} \\
\mathrm{x}\end{array}$ & & & & $\begin{array}{l}x \\
x\end{array}$ & & & & & $\begin{array}{l}\mathrm{x} \\
\mathrm{x}\end{array}$ & & $\begin{array}{l}x \\
x\end{array}$ & & $\begin{array}{l}\mathrm{x} \\
\mathrm{x}\end{array}$ & & $\begin{array}{l}\mathrm{x} \\
\mathrm{x}\end{array}$ \\
\hline $\operatorname{Jan} 31,2003$ & & $x$ & & & & $\mathrm{x}$ & & $x$ & $x$ & & & & $\mathrm{x}$ & & & & & $\mathrm{x}$ & & $x$ & & $x$ & & $x$ \\
\hline Feb 01, 2003 & & $x$ & & & & $\mathrm{x}$ & & $x$ & & & $\mathrm{x}$ & & $x$ & & \begin{tabular}{|l}
$x$ \\
\end{tabular} & & & $\mathrm{x}$ & $x$ & $x$ & & $\mathrm{x}$ & $\mathrm{x}$ & $\mathrm{x}$ \\
\hline Feb 02, 2003 & & $\bar{x}$ & & & & $\mathrm{x}$ & & $x$ & $\mathrm{x}$ & & $x$ & & $\mathrm{x}$ & & $\mathrm{x}$ & & $x$ & $\mathrm{x}$ & $\bar{x}$ & $x$ & $\mathrm{x}$ & & & $\bar{x}$ \\
\hline Feb 03, 2003 & & $\bar{x}$ & & & & $\mathrm{x}$ & & $x$ & $\mathrm{x}$ & & & & $x$ & & & & & $\mathrm{x}$ & & $x$ & & $\mathrm{x}$ & & \\
\hline Feb 04, 2003 & & & & & & $\mathrm{X}$ & & $x$ & $\mathrm{x}$ & & $\mathrm{x}$ & & & & $\mathrm{x}$ & & & $\mathrm{x}$ & $\bar{x}$ & $\mathrm{x}$ & & $\mathrm{x}$ & $\mathrm{x}$ & $\bar{x}$ \\
\hline Feb 05, 2003 & & & & & & $\mathrm{x}$ & & $x$ & & & & & $x$ & & $\mathrm{x}$ & & $x$ & $\mathrm{x}$ & $x$ & & $x$ & $\mathrm{x}$ & $\mathrm{x}$ & \\
\hline Feb 06, 2003 & & & & & & $\mathrm{x}$ & & $x$ & & & & & $x$ & & & & & $\mathrm{x}$ & $x$ & $x$ & $x$ & $\mathrm{x}$ & $\mathrm{x}$ & $x$ \\
\hline Feb 07, 2003 & & & & & & $\mathrm{x}$ & & $x$ & & & & & $\mathrm{x}$ & & $\mathrm{x}$ & & $\mathrm{x}$ & $\mathrm{x}$ & $\bar{x}$ & $\bar{x}$ & $\bar{x}$ & $\mathrm{x}$ & $\mathrm{x}$ & $\bar{x}$ \\
\hline Feb 08, 2003 & & & & & $x$ & $\mathrm{x}$ & $\mathrm{x}$ & $x$ & & & & & $x$ & & $\mathrm{x}$ & & $x$ & $\mathrm{x}$ & $\mathrm{x}$ & & $\bar{x}$ & $\mathrm{x}$ & & $\bar{x}$ \\
\hline Feb 09, 2003 & & & & & $x$ & $\mathrm{x}$ & $\mathrm{x}$ & $x$ & & & & & $x$ & & $\mathrm{x}$ & & & $\mathrm{x}$ & & $x$ & $\mathrm{x}$ & $\mathrm{x}$ & & $\bar{x}$ \\
\hline Feb 10, 2003 & & & & & $\mathrm{x}$ & & $\mathrm{x}$ & $x$ & & & & & $x$ & & $\mathrm{x}$ & & & & $x$ & $x$ & & $x$ & & \\
\hline Feb 11, 2003 & & & & & & $\mathrm{x}$ & & $x$ & & & & & $\mathrm{x}$ & & & & & $\mathrm{x}$ & & $x$ & & $\mathrm{x}$ & & $\bar{x}$ \\
\hline Feb 12, 2003 & & & & & & $\mathrm{x}$ & & $x$ & $\mathrm{x}$ & & & & $\mathrm{x}$ & & & & & $\mathrm{x}$ & & $x$ & & $\mathrm{x}$ & & $\bar{x}$ \\
\hline Feb 13, 2003 & & & & & & $\mathrm{x}$ & & $x$ & $\mathrm{x}$ & & & & $\mathrm{x}$ & & & & & $\mathrm{x}$ & & $x$ & & $\mathrm{x}$ & & $\bar{x}$ \\
\hline Feb 14, 2003 & & & & & & & & & $\mathrm{x}$ & & & & $\mathrm{x}$ & & & & & $\mathrm{X}$ & & $x$ & & $\mathrm{X}$ & & \\
\hline
\end{tabular}


TABLE 2. Error Statistics of the zonal and meridional wind at $850 \mathrm{hPa}$ from 15 December 2002 to 14 February 2003 for Santa Cruz and Mariscal.

\begin{tabular}{lcccccccc}
\hline & \multicolumn{4}{c}{ Santa Cruz } & \multicolumn{5}{c}{ Mariscal } \\
Experim. & u RMSE & u bias & v RMSE & v bias & u RMSE & u bias & v RMSE & v bias \\
\hline CDAS1 & 6.3 & -5.2 & 5.6 & 2.1 & 3.5 & 1.6 & 4.3 & 1.9 \\
CDAS1r & 3.6 & -2.7 & 4.0 & 1.8 & 2.3 & 1.0 & 2.6 & 1.0 \\
CDAS1rp & 3.9 & -3.0 & 4.1 & 2.1 & 2.4 & 1.2 & 2.5 & 0.9 \\
CDAS2 & 7.9 & -6.7 & 5.5 & 1.8 & 3.6 & 0.4 & 4.6 & 1.3 \\
CDAS2r & 4.9 & -4.0 & 3.5 & 1.2 & 2.3 & 0.5 & 2.5 & 1.0 \\
CDAS2rp & 4.9 & -3.9 & 3.9 & 1.5 & 2.4 & 0.7 & 2.6 & 1.2 \\
GDAS & 7.0 & -5.9 & 5.4 & 4.2 & 3.1 & 0.5 & 3.4 & 1.8 \\
GDASr & 2.9 & -1.9 & 1.9 & 0.9 & 1.5 & 0.1 & 1.5 & 0.0 \\
GDASrp & 3.0 & -2.0 & 2.3 & 1.0 & 2.5 & 0.1 & 2.3 & 0.6 \\
GDASp & 6.0 & -4.6 & 5.0 & 3.3 & 3.1 & 0.6 & 3.0 & 1.0 \\
\hline
\end{tabular}




\section{Figure Captions}

Fig. 1. The SALLJEX upper-air network over South America. SALLJEX rawinsonde (square), and pilot balloons (circle). Topography $(\mathrm{m})$ over South America derived from CDAS (left) and GDAS (right).

Fig. 2. Mean low-level wind (vector) and wind speed (shaded) at $850 \mathrm{hPa}$ for 15 January to 14 February 2003. a) CDAS1, b) CDAS2, c) GDAS, d) CDAS1rp, e)CDAS2rp and f) GDASrp. Values are in $\mathrm{m} \mathrm{s}^{-1}$.

Fig. 3. Mean meridional wind profile composite for control runs (red), including only rawinsonde (blue) and rawinsonde and pilot balloon (yellow) at the grid point nearest Santa Cruz, Bolivia, for 15 January to 14 February 2003. Results from GDAS: a), b), c) and d) for 00, 06, 12, and 18 UTC, respectively. Results from CDAS1: e), f), g) and h) for 00, 06, 12 and 18 UTC, respectively. Results from CDAS2: i), j), k) and I) for 00, 06, 12 and 18 UTC, respectively. Units are in $\mathrm{m} \mathrm{s}^{-1}$.

Fig. 4. Mean low-level meridional wind at $\left(18^{\circ} \mathrm{S}, 62^{\circ} \mathrm{W}\right)$ for (a) GDAS (red), GDASr (blue), GDASp (yellow) and GDASrp (green) at $900 \mathrm{hPa}$, (b) CDAS1 (red), CDASr (blue) and CDAS1rp (green) at $850 \mathrm{hPa}$ and (c) CDAS2 (red), CDAS2r (blue) and CDAS2rp (green) at $850 \mathrm{hPa}$. Units are in $\mathrm{m} \mathrm{s}^{-1}$.

Fig. 5. Same as Figure 3, but for the grid point nearest Mariscal, Paraguay.

Fig. 6. Vertical profile of meridional wind at Mariscal, with observed data in blue, CDAS2 (red long dash), CDASrp (dark yellow), GDAS (black long dash) and GDASrp (green) for 18 UTC 22 January, 00 UTC 23 January and 06 UTC 23 January. Units are in $\mathrm{m} \mathrm{s}^{-1}$.

Fig. 7. Cross sections of moisture fluxes (qv) along $22^{\circ} S$ (near Mariscal) for 18 UTC 22 January, 00 UTC 23 January and 06 UTC 23 January for GDAS (top panel) and GDASrp (bottom panel). Contour interval is $30 \mathrm{~g} \mathrm{~kg}^{-1} \mathrm{~m} \mathrm{~s}^{-1}$.

Fig. 8 . Vertical velocity at $700 \mathrm{hPa}$ for GDAS (a), GDASrp (b) and CMORPH precipitation (c). Vertical velocity intervals are in $0.5 \mathrm{~Pa} \mathrm{~s}^{-1}$ and precipitation is contoured at irregular intervals of $1,5,10$ e $20 \mathrm{~mm} \mathrm{~h}^{-1}$., for the same time 06 UTC 23 January 2003.

Fig. 9. Time series of $850-\mathrm{hPa}$ specific humidity at the grid point nearest Santa Cruz for 15 December 2002 to 14 February 2003 from a) GDAS (green) and GDASrp (red) and the difference between them. The observational values are indicated by blue triangles. b) Same as in a), except for CDAS1 and CDAS1rp. c) 
Same as in a), except for CDAS2 and CDAS2rp. The differences between the analyses with SALLJEX data and the control analyses are plotted at the bottom of each panel. Units are in $\mathrm{g} \mathrm{Kg}^{-1}$.

Fig. 10. Time series of $850-\mathrm{hPa}$ meridional wind at the grid point nearest Santa Cruz for 15 December 2002 to 14 February 2003 for a) GDAS (shading), GDASrp (red line), b) CDAS1 (shading), CDAS2rp (red line) and c) CDAS2 (shading), CDAS2rp (red line). The observational values are indicated by green triangles. Units are in $\mathrm{m} \mathrm{s}^{-1}$.

Fig. 11. Same as Figure 9, but for the grid point nearest Mariscal, Paraguay.

Fig. 12. Same as Figure 10, but for the grid point nearest Mariscal, Paraguay.

Fig. 13. Time series of the meridional moisture flux at $850 \mathrm{hPa}$ from a) CDAS1 (red line), CDAS2 (yellow line) and GDAS (blue line) for the grid point nearest Mariscal. b) Same as in a), except for CDAS1rp, CDAS2rp and GDASrp. c) Same as a), except for the grid point nearest Santa Cruz. d) Same as in b), except for the grid point nearest Santa Cruz. Observational values are in green. Units are in $\left(\mathrm{m} \mathrm{s}^{-1} \mathrm{~g} \mathrm{~kg}^{-1}\right)$.

Fig. 14. Mean 850-hPa wind difference between GDAS and GDASr for four synoptic times (left hand panels) and vertical zonal cross sections of meridional wind at $18^{\circ} \mathrm{S}$ (right hand panels) for 15 January to 14 February 2003. Values are in $\mathrm{m} \mathrm{s}^{-1}$.

Fig. 15. Same as Figure 14, excpet for the difference between GDAS and GDASp. 


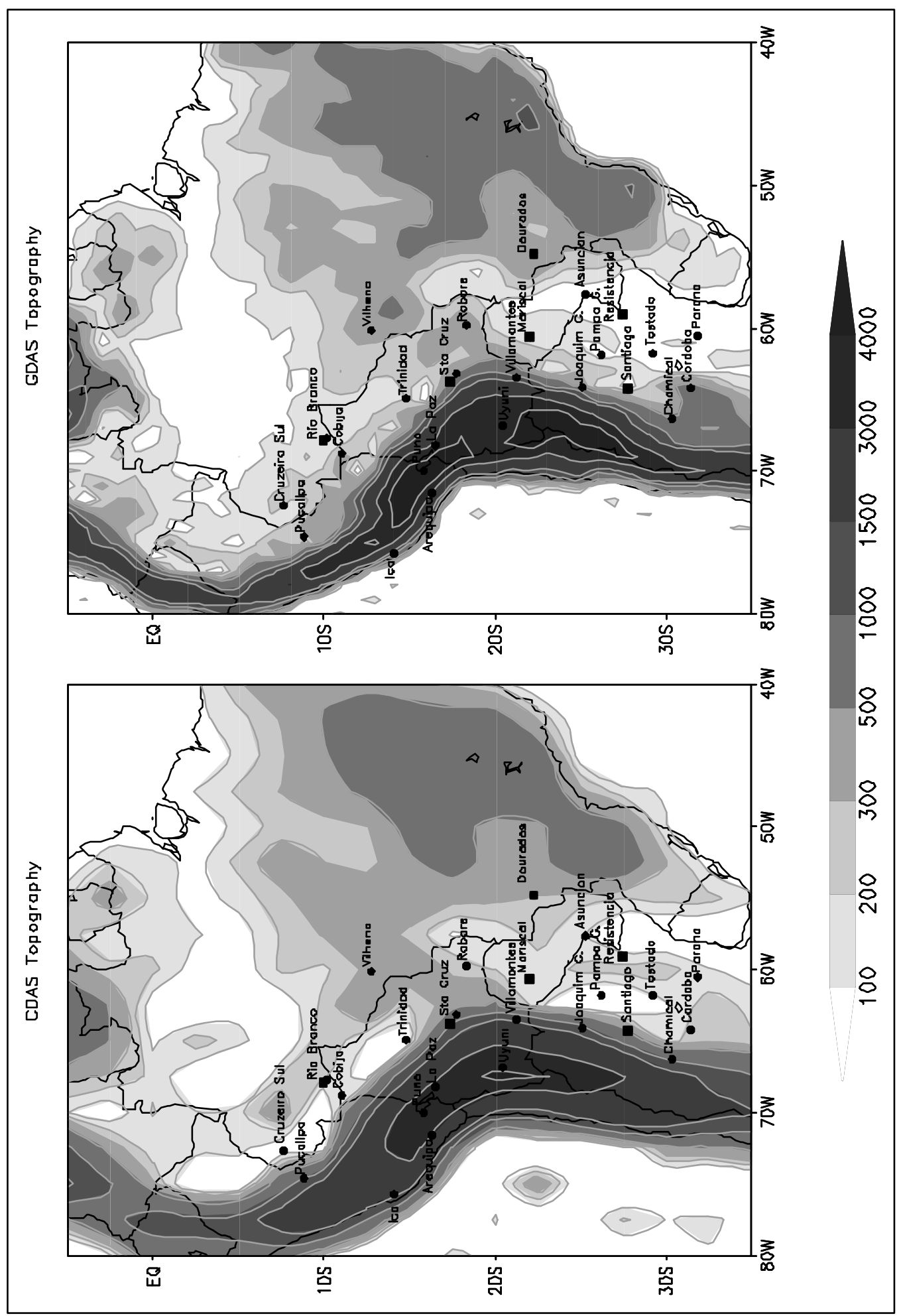

Fig. 1. The SALLJEX upper-air network over South America. SALLJEX rawinsonde (square), and pilot balloons (circle). Topography $(\mathrm{m})$ over South America derived from CDAS (left) and GDAS (right). 


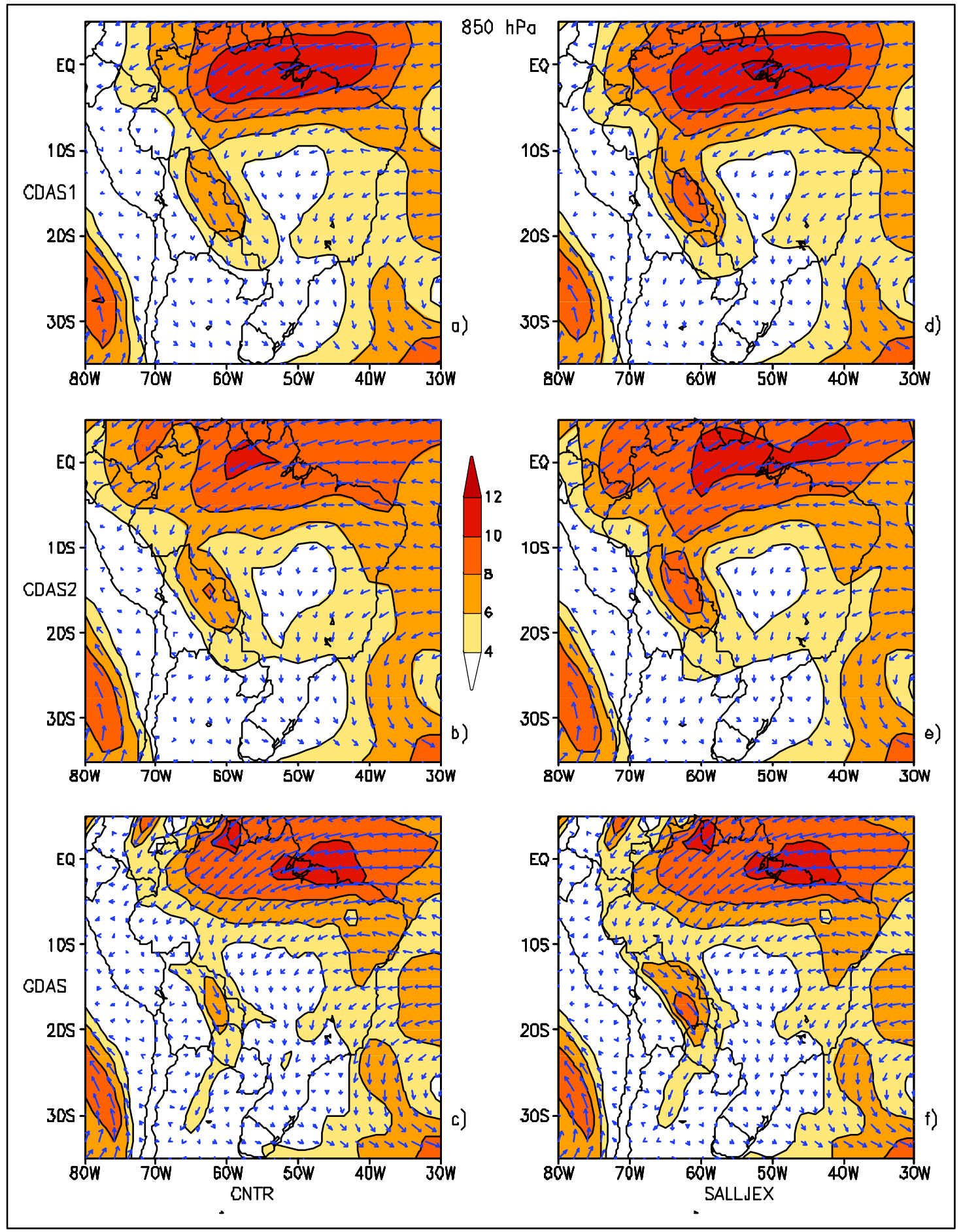

Fig. 2. Mean low-level wind (vector) and wind speed (shaded) at $850 \mathrm{hPa}$ for 15 January to 14 February 2003. a) CDAS1, b) CDAS2, c) GDAS, d) CDAS1rp, e)CDAS2rp and f) GDASrp. Values are in $\mathrm{m} \mathrm{s}^{-1}$. 

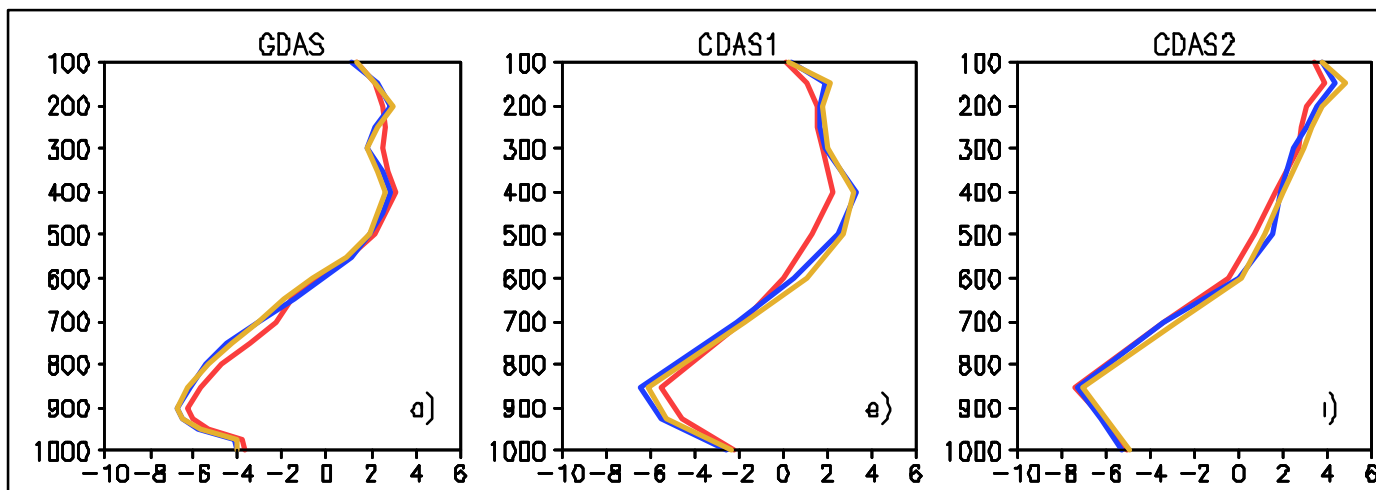

$00 Z$
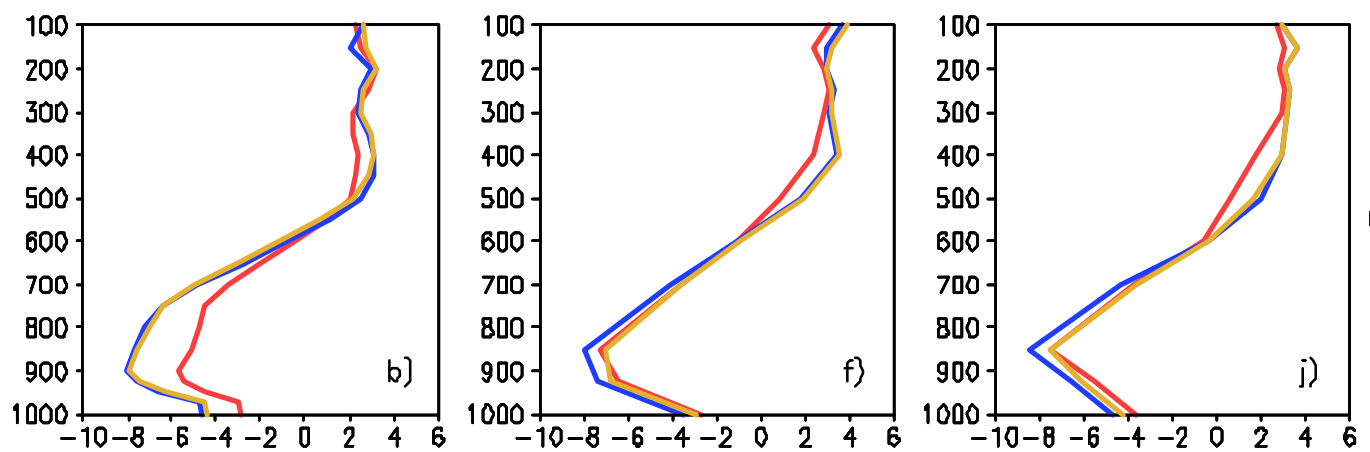

$06 Z$
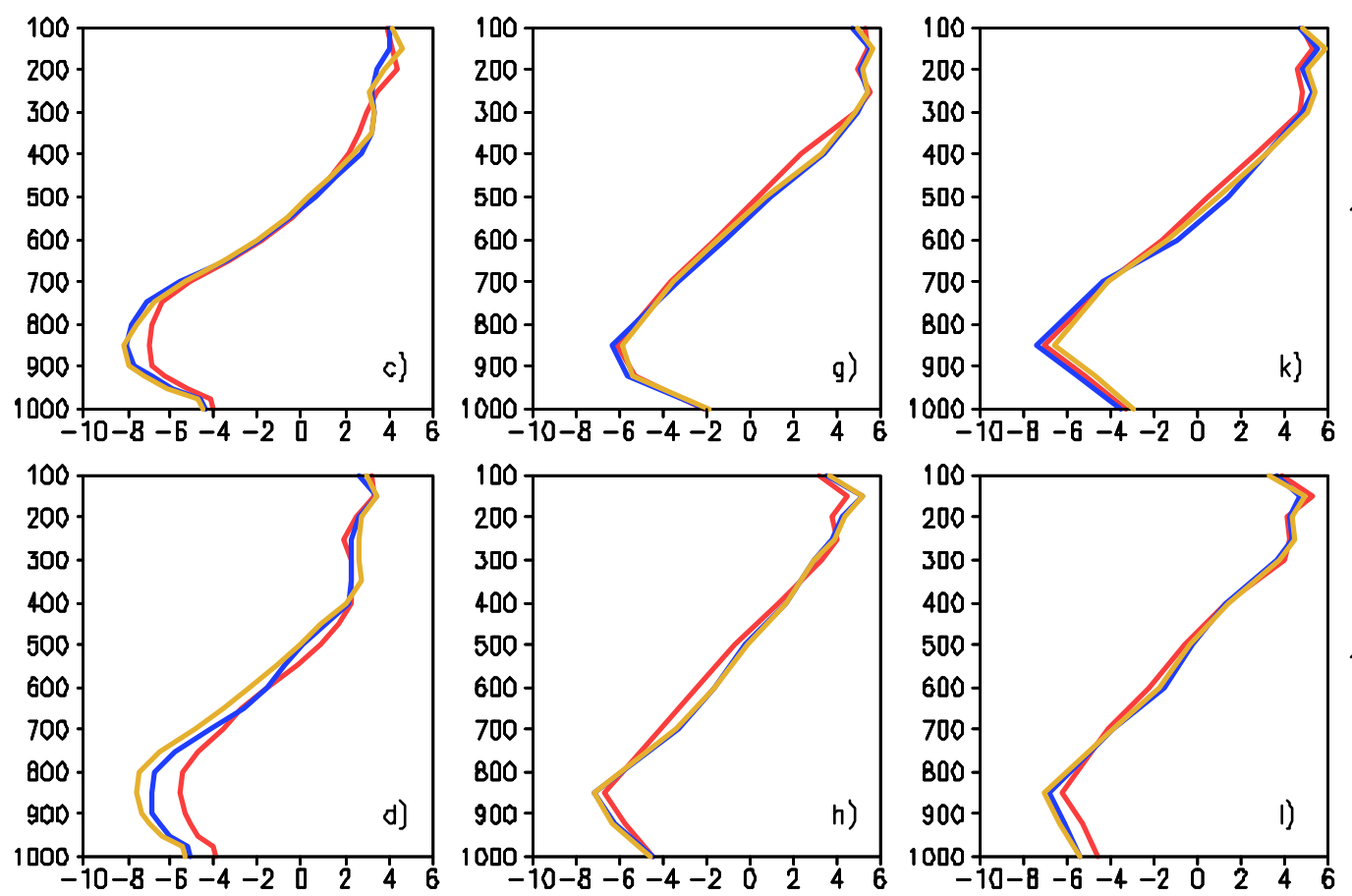

Fig. 3. Mean meridional wind profile composite for control runs (red), including only rawinsonde (blue) and rawinsonde and pilot balloon (yellow) at the grid point nearest Santa Cruz, Bolivia, for 15 January to 14 February 2003. Results from GDAS: a), b), c) and d) for 00, 06, 12, and 18 UTC, respectively. Results from CDAS1: e), f), g) and h) for 00, 06, 12 and 18 UTC, respectively. Results from CDAS2: i), j), k) and I) for 00, 06, 12 and 18 UTC, respectively. Units are in $\mathrm{m} \mathrm{s}^{-1}$. 


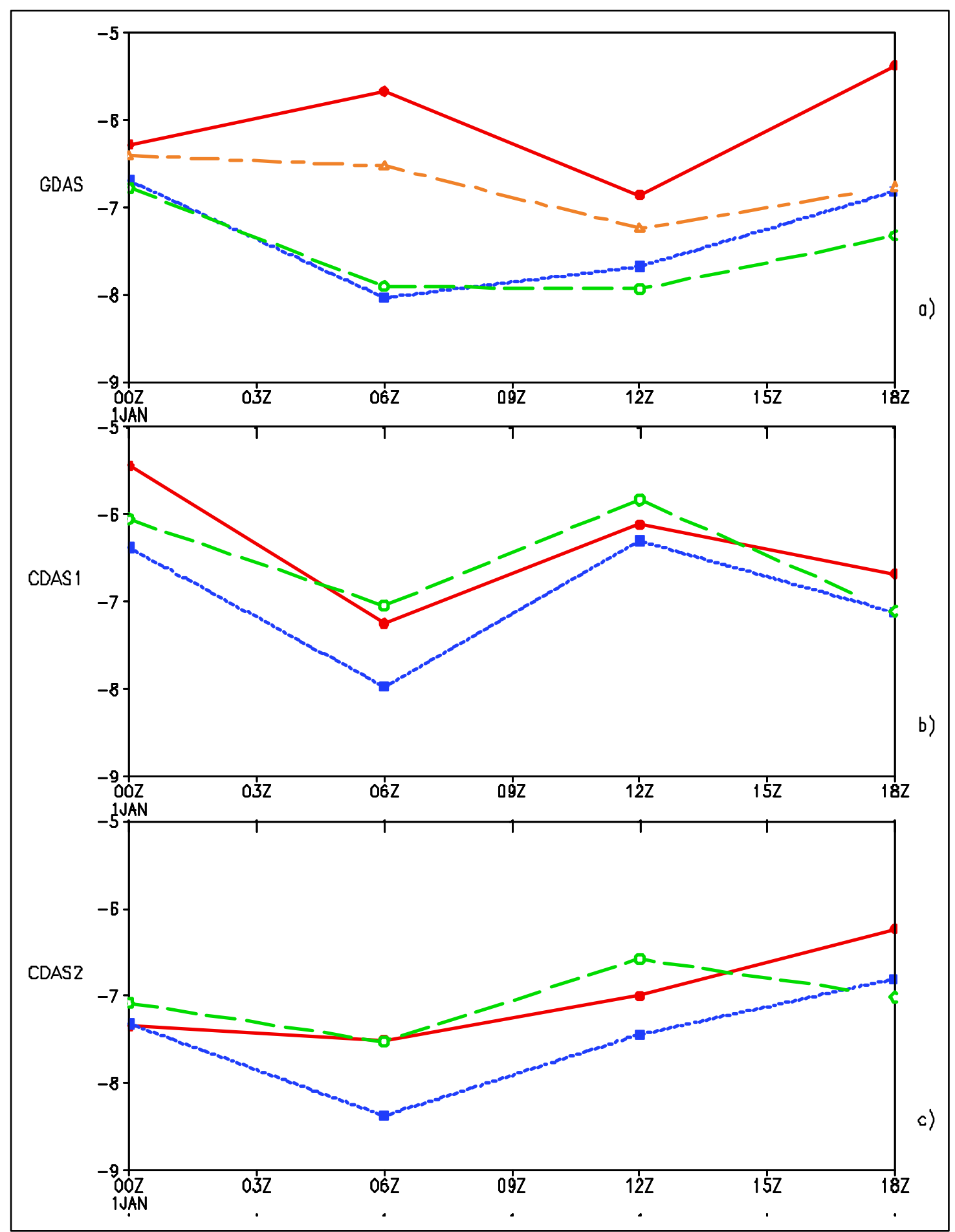

Fig. 4. Mean low-level meridional wind at $\left(18^{\circ} \mathrm{S}, 62^{\circ} \mathrm{W}\right)$ for (a) GDAS (red), GDASr (blue), GDASp (yellow) and GDASrp (green) at $900 \mathrm{hPa}$, (b) for CDAS1 (red), CDAS1r (blue) and CDAS1rp (green) at $850 \mathrm{hPa}$ and (c) CDAS2 (red), CDAS2r (blue) and CDAS2rp (green) at $850 \mathrm{hPa}$. Units are in $\mathrm{m} \mathrm{s}^{-1}$. 


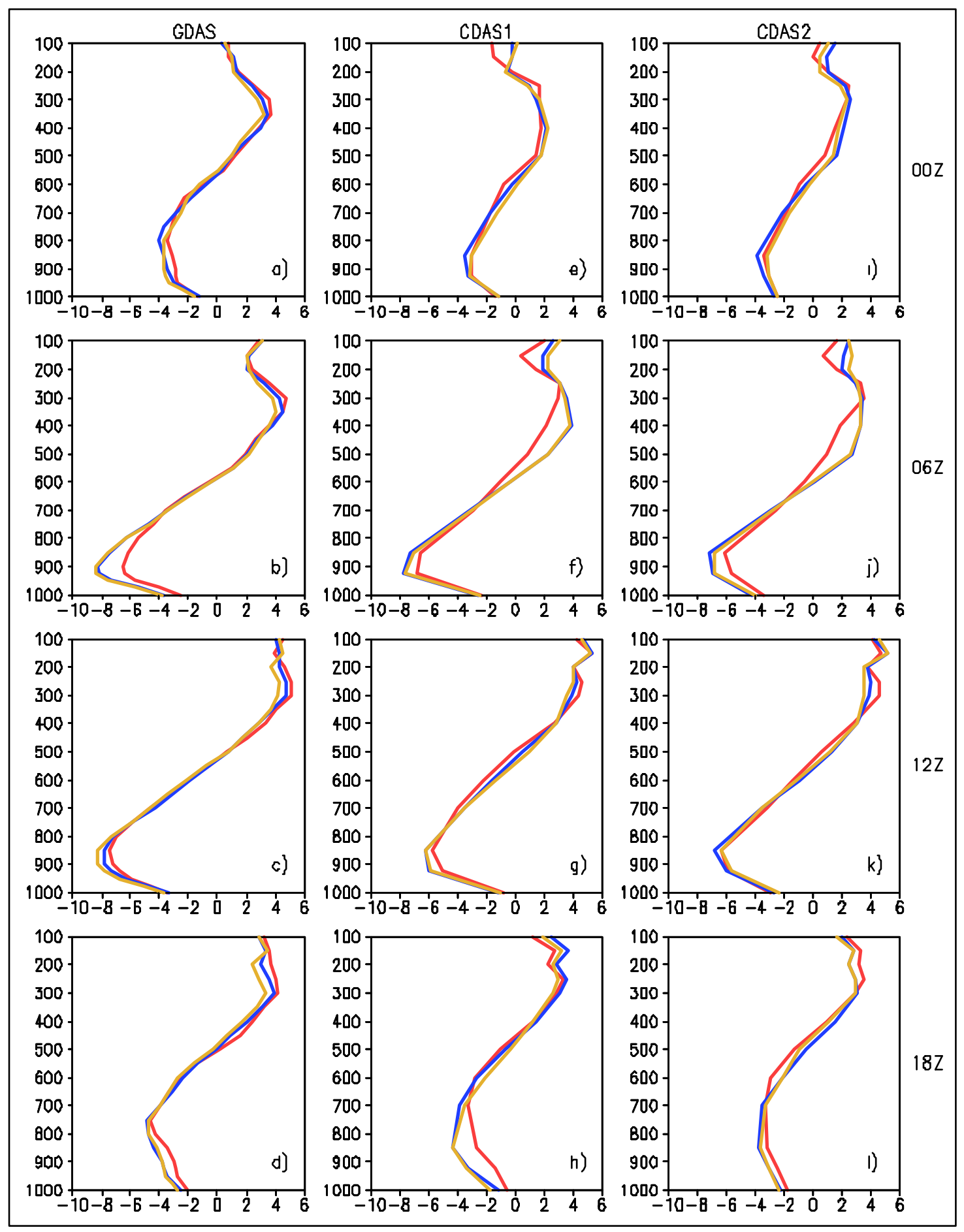

Fig. 5. Same as Figure 3, but for the grid point nearest Mariscal, Paraguay. 


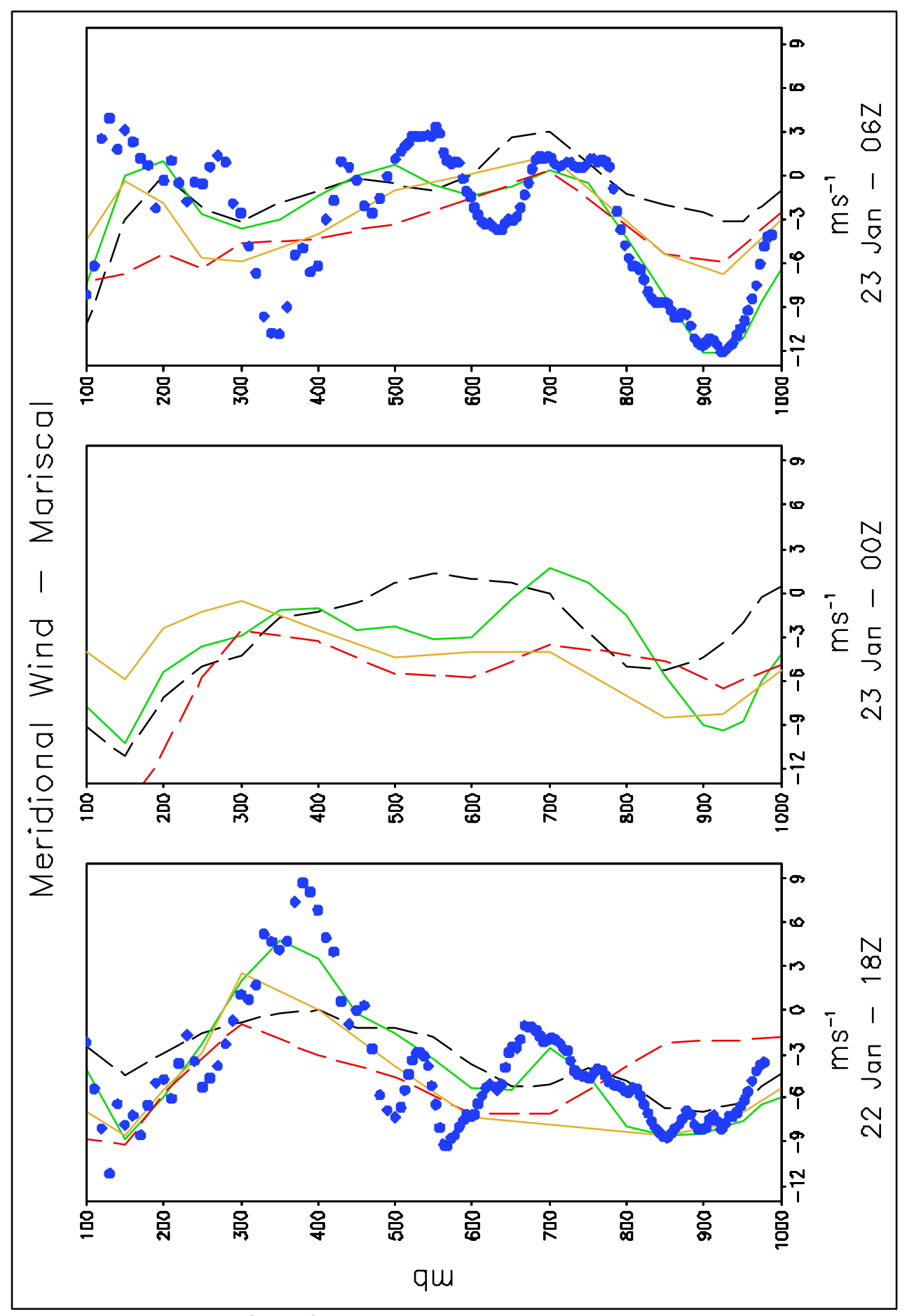

Fig. 6. Vertical profile of meridional wind at Mariscal, with observed data in blue, CDAS2 (red long dash), CDASrp (dark yellow), GDAS (black long dash) and GDASrp (green) for 18 UTC 22 January, 00 UTC 23 January and 06 UTC 23 January. Units are in $\mathrm{m} \mathrm{s}^{-1}$. 


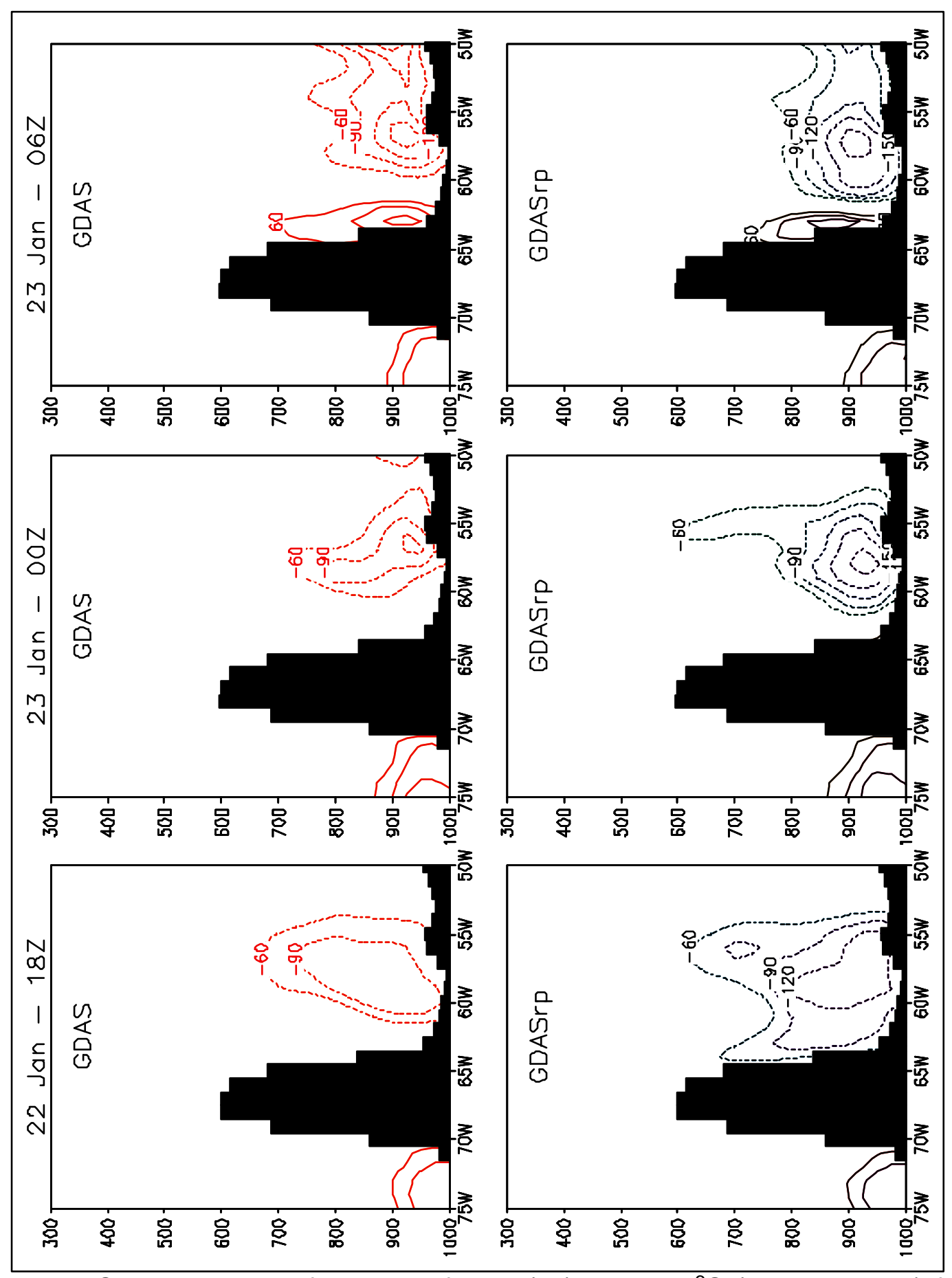

Fig 7. Cross sections of moisture fluxes (qv) along $22^{\circ} \mathrm{S}$ (near Mariscal) for 18 UTC 22 January, 00 UTC 23 January and 06 UTC 23 January for GDAS (top panel) and GDASrp (bottom panel). Contour interval is $30 \mathrm{~g} \mathrm{~kg}^{-1} \mathrm{~m} \mathrm{~s}^{-1}$. 


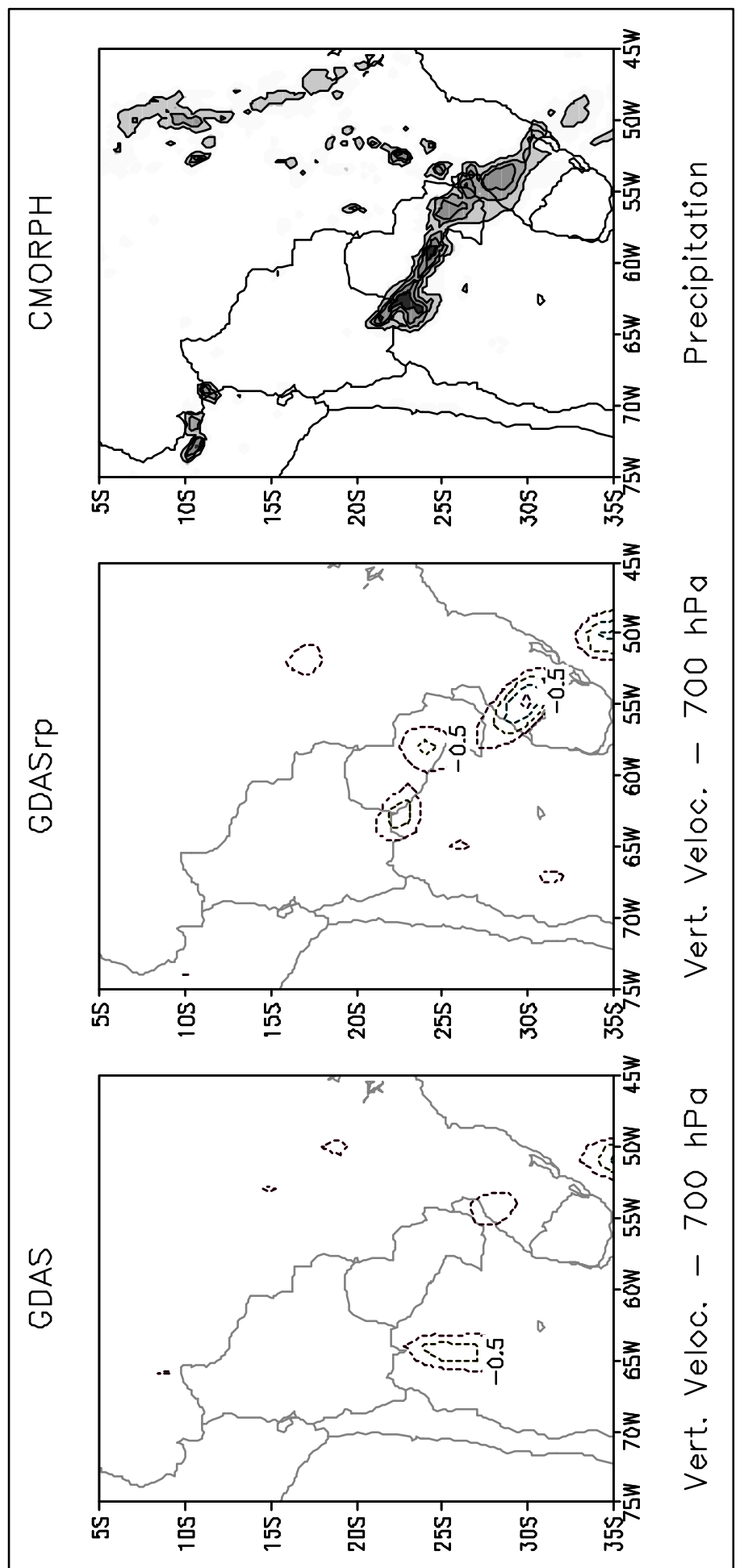

Fig. 8. Vertical velocity at $700 \mathrm{hPa}$ for GDAS (a), GDASrp (b) and CMORPH precipitation (c). Vertical velocity intervals are in $0.5 \mathrm{~Pa} \mathrm{~s}^{-1}$ and precipitation is contoured at irregular intervals of $1,5,10$ e $20 \mathrm{~mm} \mathrm{~h}^{-1}$., for the same time 06 UTC 23 January 2003. 


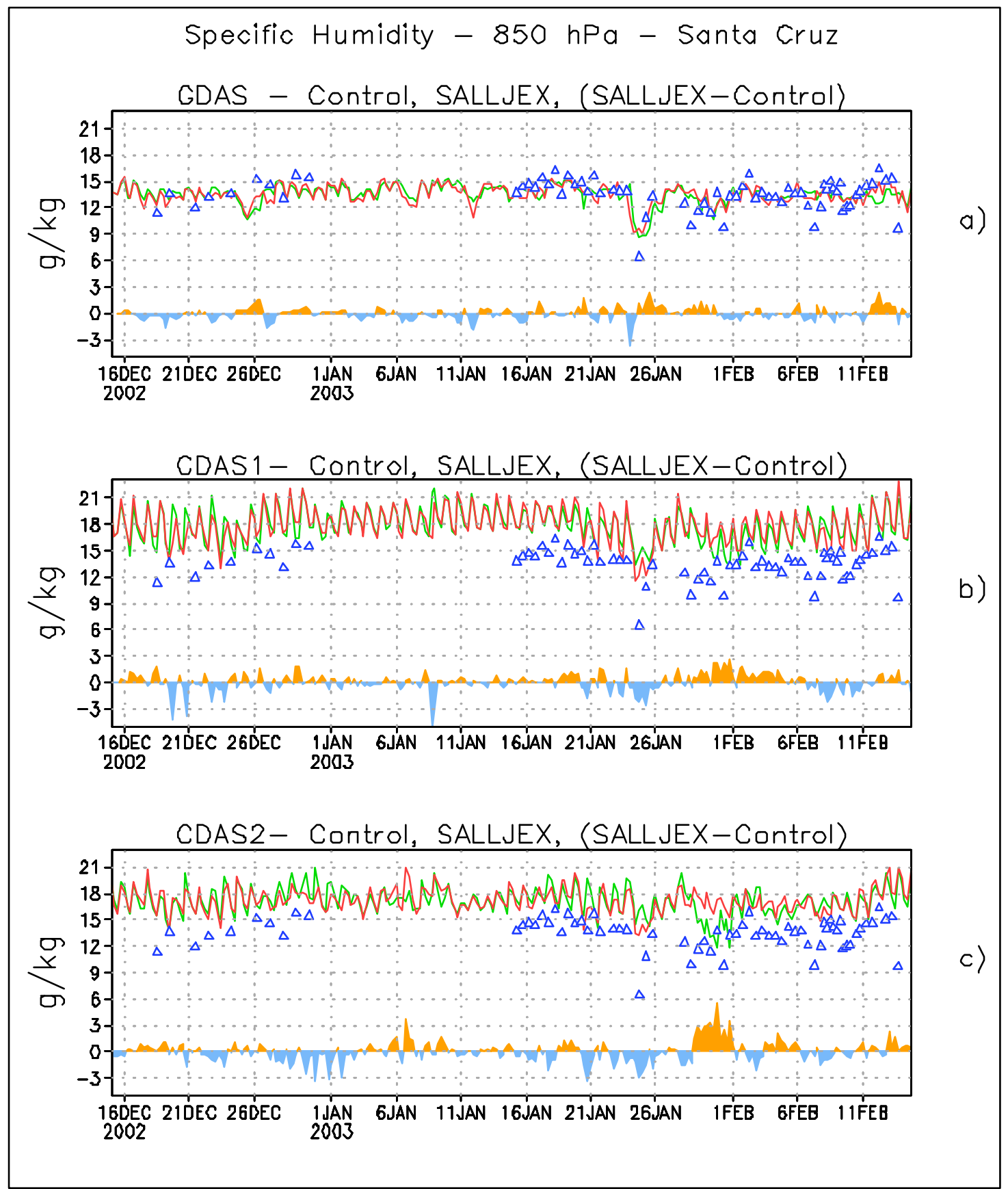

Fig. 9. Time series of $850 \mathrm{hPa}$ specific humidity at the grid point nearest Santa Cruz for 15 December 2002 to 14 February 2003 from a) GDAS (green) and GDASrp (red) and the difference between then. The observational values are indicated by blue triangles. b) Same as in a), except for CDAS1 and CDAS1rp. c) Same as in a) except for CDAS2 and CDAS2rp. The differences between the analyses with SALLJEX data and the control analyses are plotted at the bottom of each panel. Units are in $\mathrm{g} \mathrm{Kg}^{-1}$. 


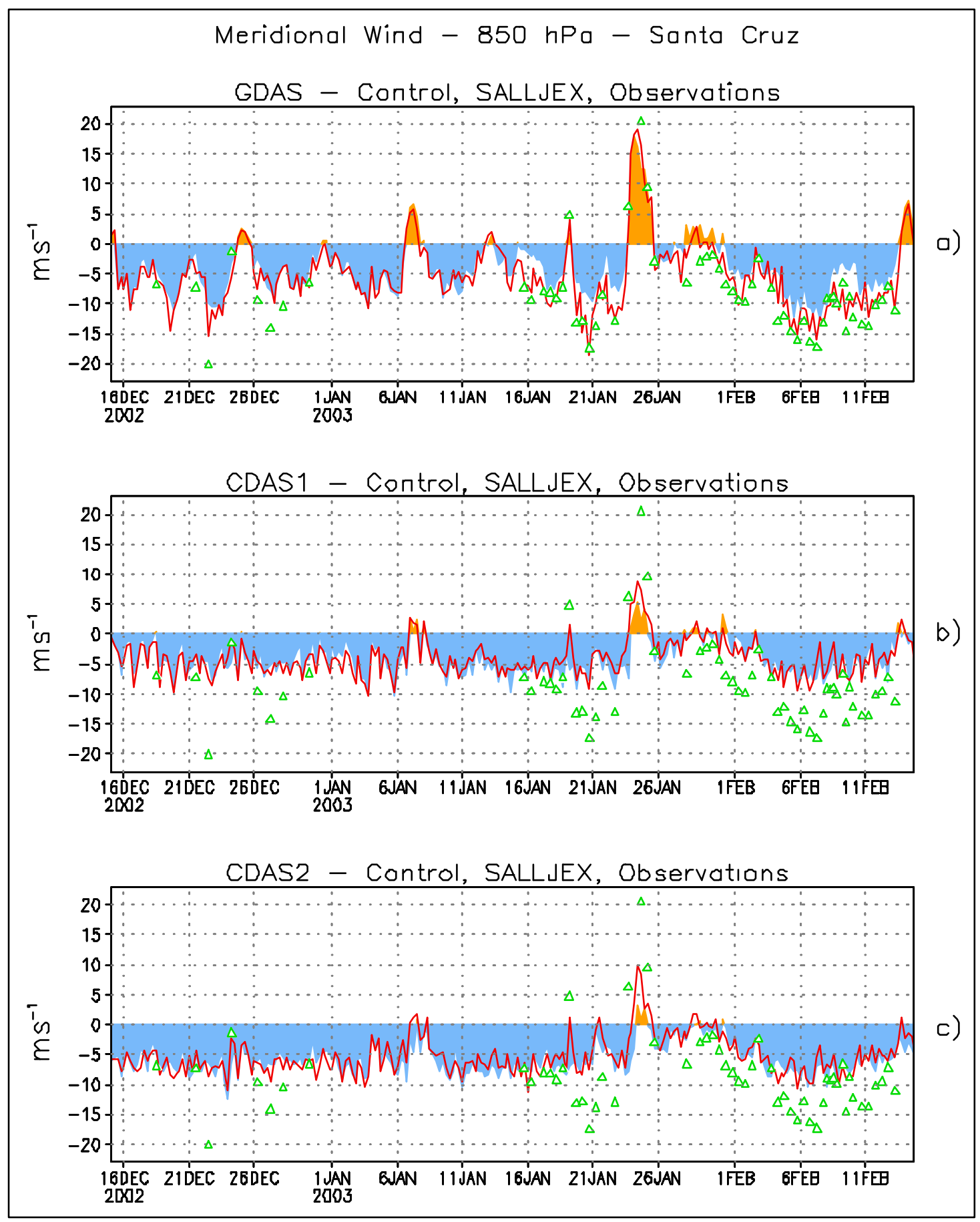

Fig. 10. Time series of $850 \mathrm{hPa}$ meridional wind at the grid point nearest Santa Cruz for 15 December 2002 to 14 February 2003 for a) GDAS (shading), GDASrp (red line), b) CDAS1 (shading), CDAS2rp (red line) and c) CDAS2 (shading), CDAS2rp (red line). The observational values are indicated by green triangles. Units are in $\mathrm{m} \mathrm{s}^{-1}$. 


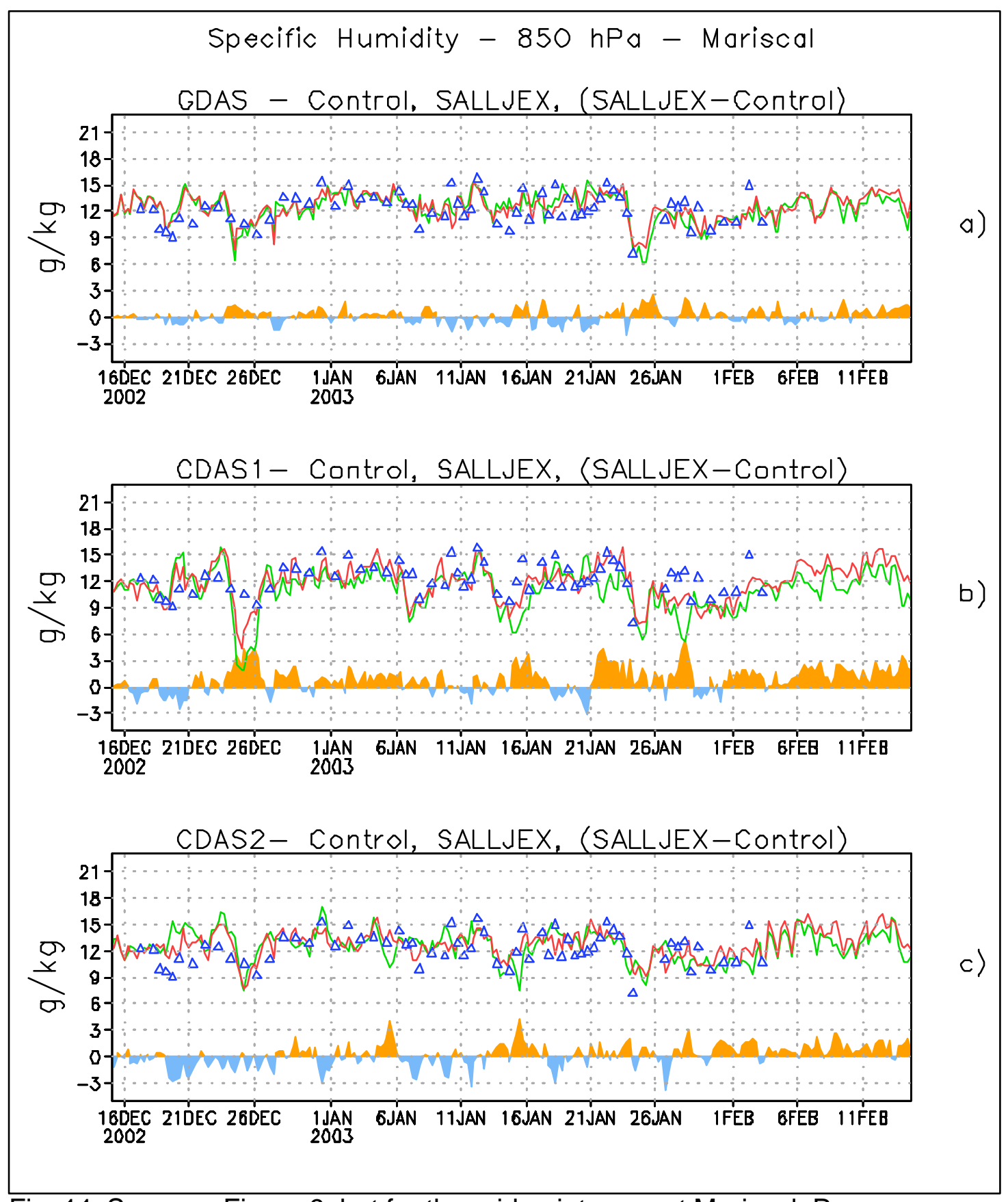

Fig. 11. Same as Figure 9, but for the grid point nearest Mariscal, Paraguay. 


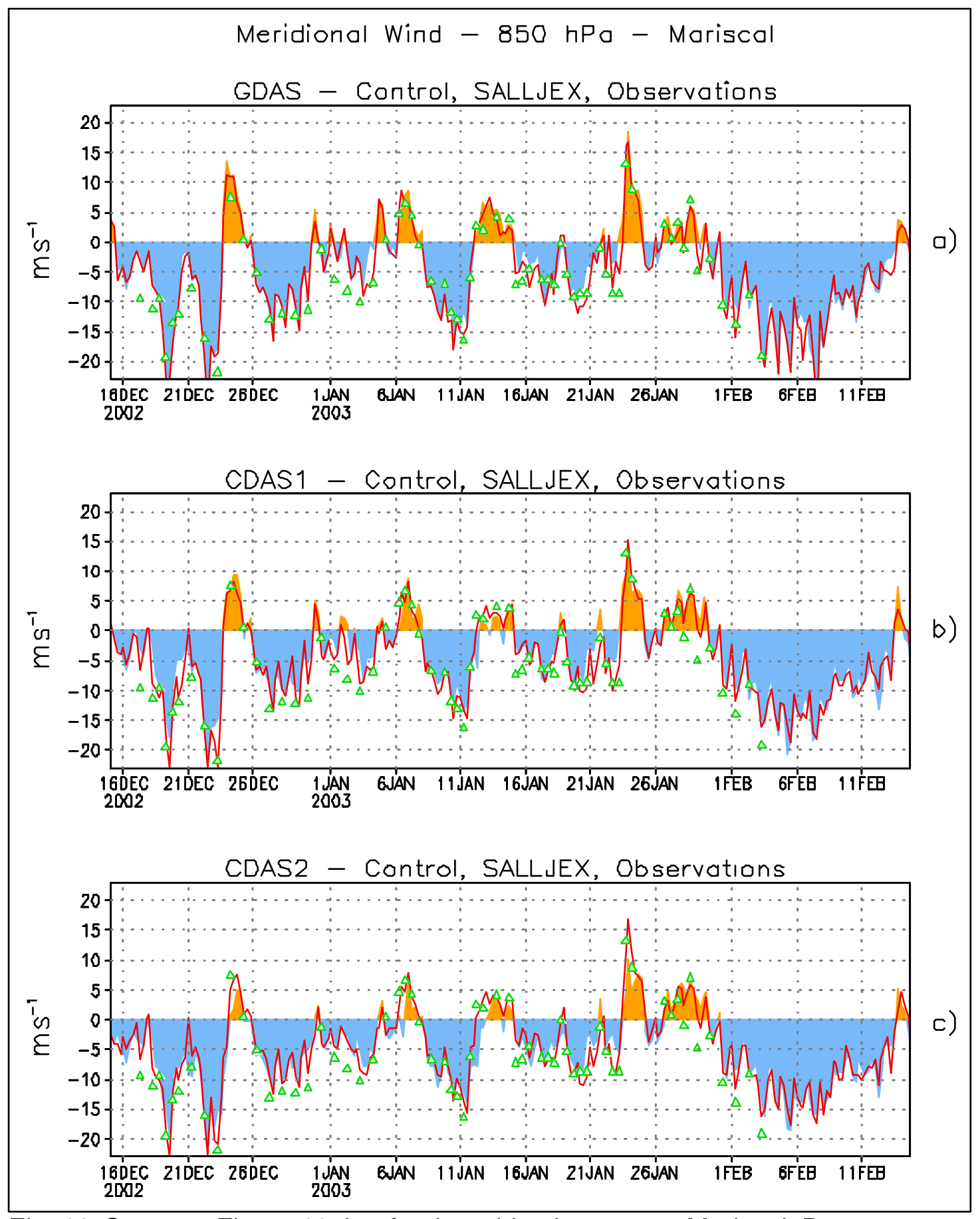

Fig. 12. Same as Figure 10, but for the grid point nearest Mariscal, Paraguay. 


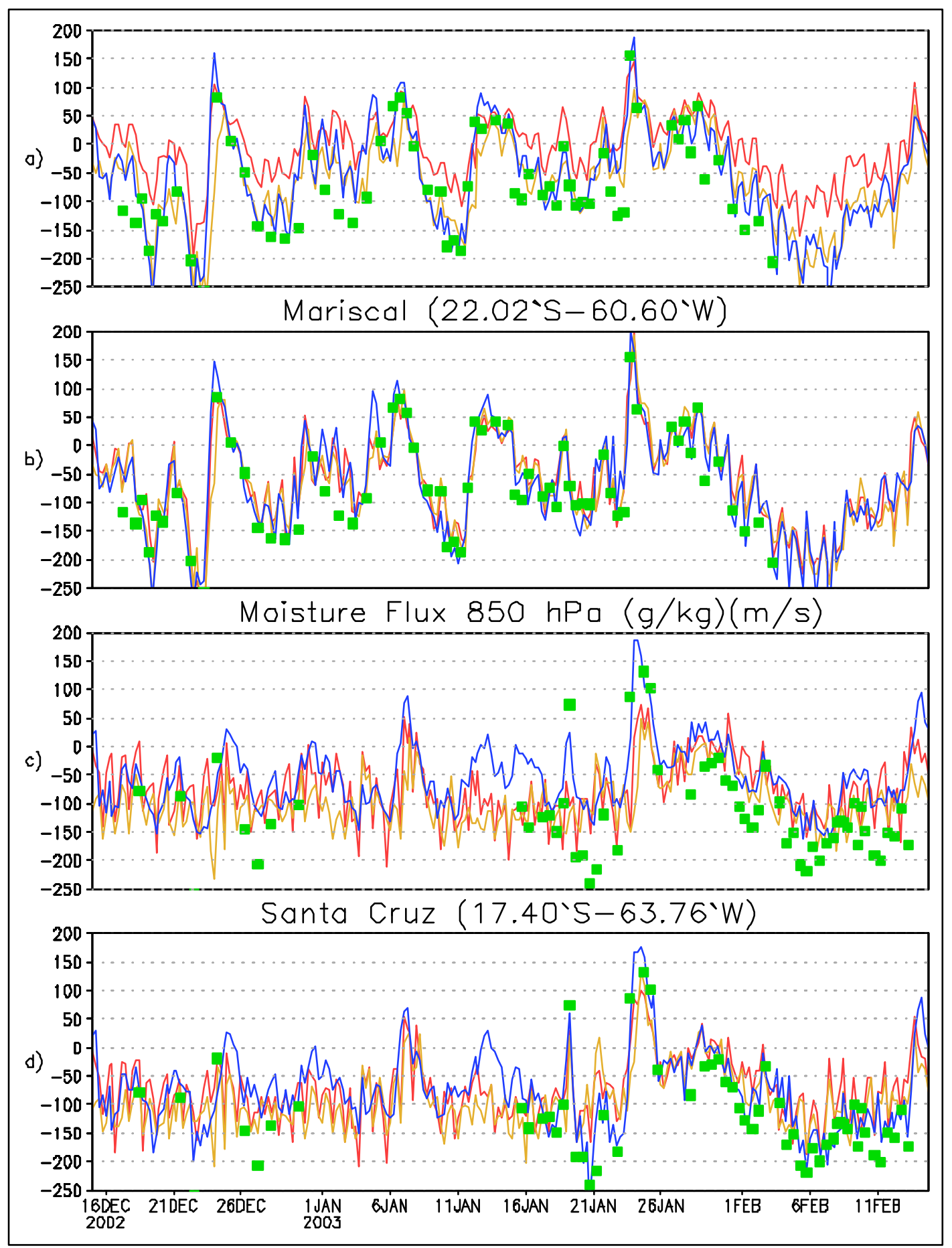

Fig. 13. Time series of the meridional moisture flux at $850 \mathrm{hPa}$ from a) CDAS1 (red line), CDAS2 (yellow line) and GDAS (blue line) for the grid point nearest Mariscal. b) Same as in a), except for CDAS1rp, CDAS2rp and GDASrp. c) Same as a), except for the grid point nearest Santa Cruz. d) Same as in b), except for the grid point nearest Santa Cruz. Observational values are in green. Units are in $\left(\mathrm{m} \mathrm{s}^{-1} \mathrm{~g} \mathrm{~kg}^{-1}\right)$. 

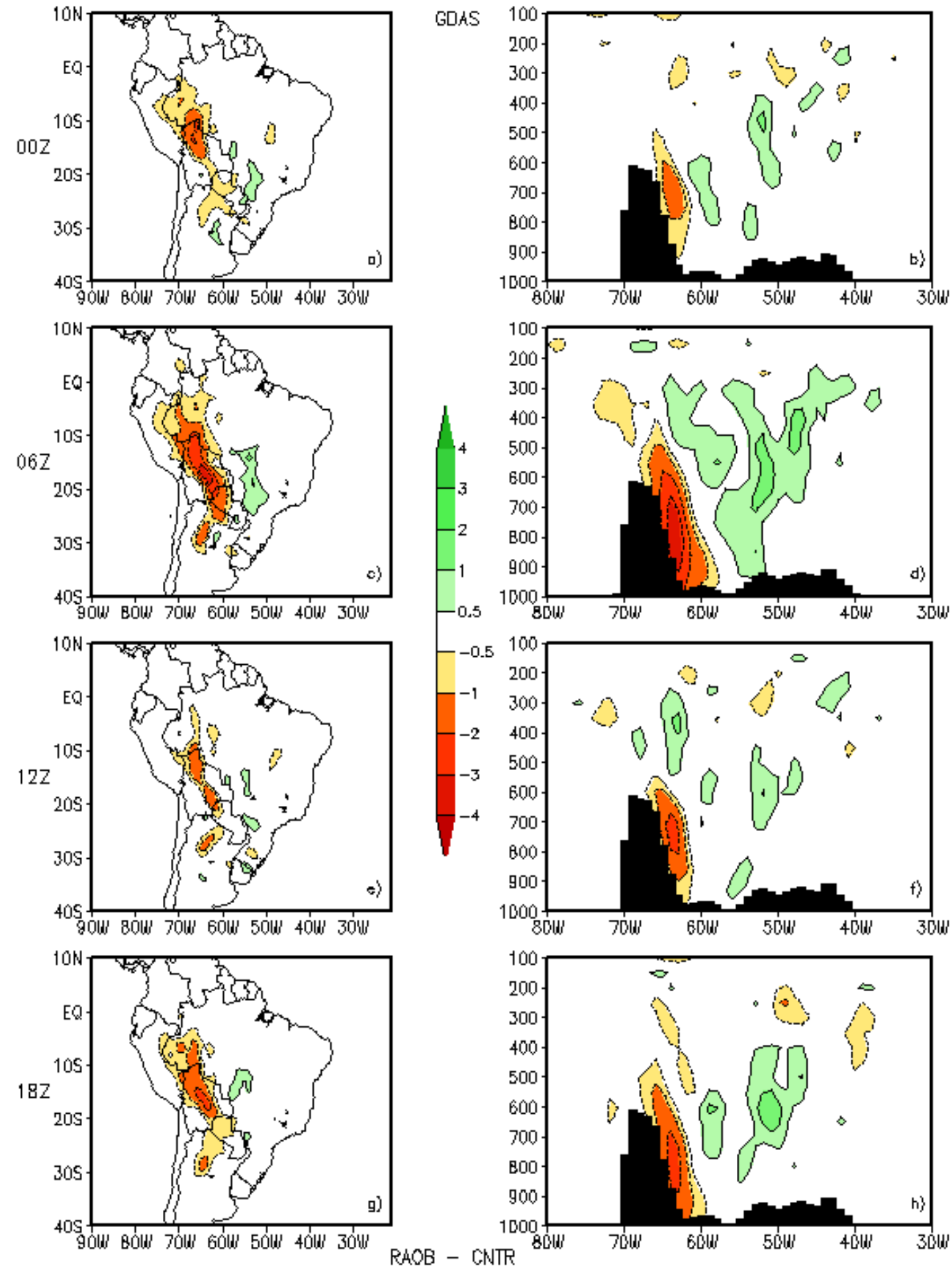

Fig. 14. Mean 850-hPa wind difference between GDAS and GDASr for four synoptic times (left hand panels) and vertical zonal cross sections of meridional wind at $18^{\circ} \mathrm{S}$ (right hand panels) for 15 January to 14 February 2003 . Values are in $\mathrm{m} \mathrm{s}^{-1}$. 

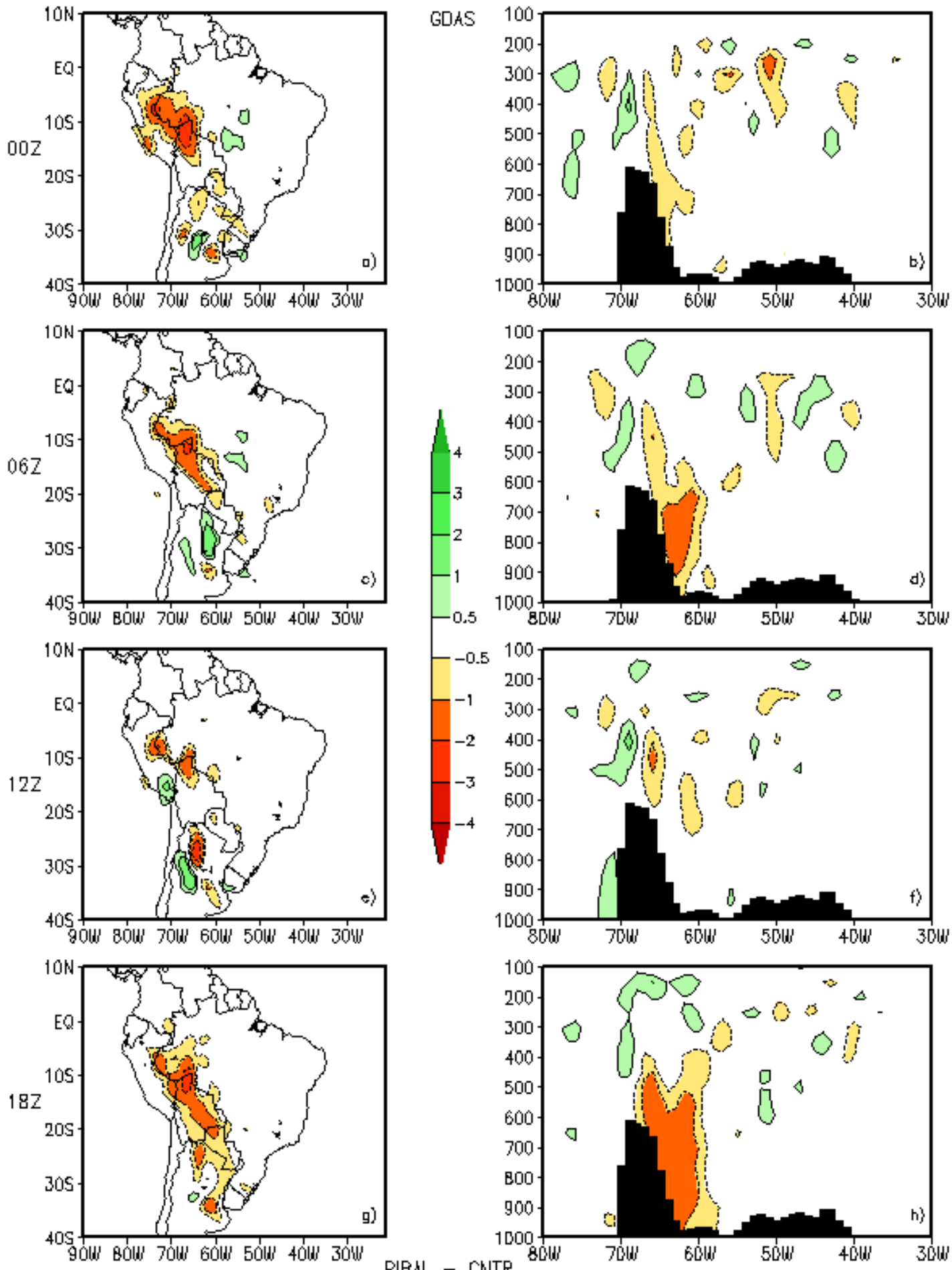

PIBAL - CNTR

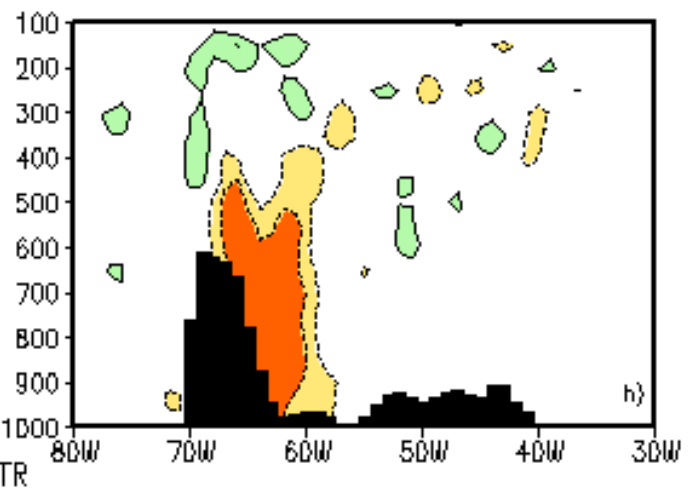

Fig. 15. Same as Figure 14, except for the difference between GDAS and GDASp. 